TI 2017-006/VII

Tinbergen Institute Discussion Paper
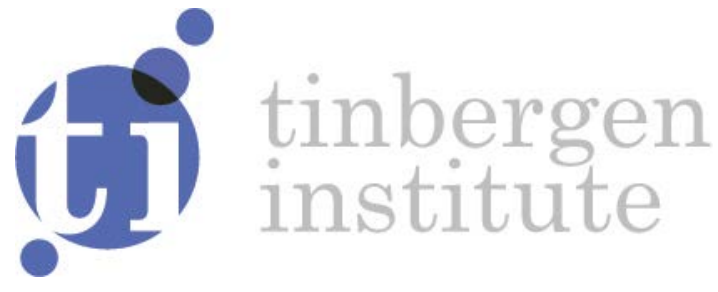

\title{
The Origins and Extent of Entrepreneurial Action-Orientedness: An Experimental Study
}

\author{
Ahmad Barirani ${ }^{1}$ \\ Randolph Sloof ${ }^{2,5}$ \\ Mirjam Van Praag ${ }^{1,3,4,5}$
}

${ }^{1}$ Department of Innovation and Organizational Economics (INO), Copenhagen Business School, 2000 Frederiksberg, Denmark

${ }^{2}$ Amsterdam School of Economics, University of Amsterdam, 1018 WB Amsterdam, The Netherlands

${ }^{3}$ Center for Economic and Policy Research (CEPR), 1611 Connecticut Avenue, Washington, DC, United States ${ }^{4}$ Institute for the Study of Labor (IZA), 53113 Bonn, Germany

${ }^{5}$ Tinbergen Institute, 3062 PA Rotterdam, The Netherlands 
Tinbergen Institute is the graduate school and research institute in economics of Erasmus University Rotterdam, the University of Amsterdam and VU University Amsterdam.

Contact: discussionpapers@tinbergen.nl

More TI discussion papers can be downloaded at http://www.tinbergen.nl

Tinbergen Institute has two locations:

Tinbergen Institute Amsterdam

Gustav Mahlerplein 117

1082 MS Amsterdam

The Netherlands

Tel.: $+31(0) 205984580$

Tinbergen Institute Rotterdam

Burg. Oudlaan 50

3062 PA Rotterdam

The Netherlands

Tel.: +31(0)104088900 


\title{
The Origins and Extent of Entrepreneurial Action-Orientedness: An Experimental Study
}

\author{
Ahmad Barirani ${ }^{1}$, Randolph Sloof ${ }^{2,5}$, and Mirjam Van Praag*1,3,4,5 \\ ${ }^{1}$ Department of Innovation and Organizational Economics (INO), Copenhagen \\ Business School, 2000 Frederiksberg, Denmark \\ ${ }^{2}$ Amsterdam School of Economics, University of Amsterdam, 1018 WB \\ Amsterdam, The Netherlands \\ ${ }^{3}$ Center for Economic and Policy Research (CEPR), 1611 Connecticut Avenue, \\ Washington, DC, United States \\ ${ }^{4}$ Institute for the Study of Labor (IZA), 53113 Bonn, Germany \\ ${ }^{5}$ Tinbergen Institute, 3062 PA Rotterdam, The Netherlands
}

January 2, 2017

\begin{abstract}
We test the hypothesis, based on popular and theoretical perspectives, that entrepreneurs are more action-oriented than other occupational groups. We compare their playing strategies in an optimal stopping game using a randomized online experiment among 100s of entrepreneurs, managers and employees. Our experimental results show that entrepreneurs are indeed more action-oriented than others. We theorize that this is driven by their lower levels of loss aversion and higher levels of curiosity. Our empirical test results show that (i) entrepreneurs score indeed higher, on average, than managers and employees on curiosity and lower on loss aversion; (ii) the difference in action-orientedness between entrepreneurs and others vanishes when controlling for individual curiosity levels and (iii) an alternative treatment that provides subjects with counterfactual information (about what would have happened in case of stopping) increases their willingness to stop. Under some assumptions, the combination of these results leads to the conclusion that the higher action-orientedness of entrepreneurs can be linked to their greater curiosity, but not to their lower level of loss aversion. Hence, we find support for the intuitive idea that (curiosity driven) action-orientedness enhances the identification and/or exploitation of opportunities.
\end{abstract}

\footnotetext{
*Corresponding author: mvp.ino@cbs.dk. We are grateful to Martin Koudstaal, Massimo Colombo, Francesca Melillo, Thomas Åstebro, Stefano Brusoni, as well as participants to the 2016 DRUID Academy Conference, the Third International ZEW Conference on the Dynamics of Entrepreneurship and the 2016 Strategy, Entrepreneurship \& Innovation Doctoral Consortium for helpful comments. Research assistance was provided by Fleur Sachse and Tim van der Weert.
} 


\section{Introduction}

Are entrepreneurs less plagued by indecisiveness and inertia than other people? Popular and theoretical perspectives tend to answer this question with the affirmative. It seems unnatural to believe that entrepreneurs would suffer from the same reluctance to act upon opportunities as the general population (McMullen and Shepherd, 2006; Shane and Venkataraman, 2000). In fact, it can be argued that business opportunities do not exist per se but arise out of entrepreneurial action (Sarasvathy, 2001; Baker and Nelson, 2005). ${ }^{1}$

In general, when facing difficult choices, many people become hesitant and prefer not to do anything (Samuelson and Zeckhauser, 1988; Spranca et al., 1991). Inactivity may be attractive because it gives the illusion that one is less responsible for harmful outcomes. As a result, one feels as if blame can be evaded by choosing options that appear to be omitting involvement with the course of events (Ritov and Baron, 1995; Baron and Ritov, 2004). The tendency for inaction can thus be explained by reference-dependent preferences (Baron and Ritov, 1994): the disutility from blame for actions with undesirable outcomes is larger than the utility from rewards for actions with desirable outcomes as compared to the reference point of inaction. Despite these psychic benefits, one can feel like inaction leads to missing knowledge about outcomes and prefer action out of curiosity even at the cost of finding out that a bad decision was made (Zeelenberg et al., 2002; Van Dijk and Zeelenberg, 2007). Curiosity is thus an opposing force to blame avoidance and can lead to taking more action.

One can therefore argue that entrepreneurs are less prone to inaction because they exhibit a greater tendency for explorative search and curiosity (Laureiro-Martínez et al., 2013) and are less loss averse (Koudstaal et al., 2015) than others. Consequentially, differences in actionorientedness between entrepreneurs and others should become less prominent or disappear when controlling for individual curiosity and loss aversion.

Although the idea of associating entrepreneurship with action-orientedness is appealing, it has little empirical support. Action-orientedness is difficult to measure in reality. In the case of entrepreneurship, for example, one can start a new venture simply because an attractive opportunity is perceived without having any particular tendency to take action. On the contrary, it might also be that action-orientedness is related to opportunity recognition or the tendency to exploit opportunities. For this reason, biases towards inaction are mostly studied in hypothetical settings (Ritov and Baron, 1990; Patt and Zeckhauser, 2000; Tanner and Medin, 2004). This does not often lead to findings that are relevant from an economic perspective because incentives are lacking.

In this study, these challenges are met by resorting to an incentive-compatible controlled

\footnotetext{
${ }^{1}$ Among notable social scientists, Keynes (1936, p. 163) held the view that "... human decisions affecting the future, whether personal or political or economic, cannot depend on strict mathematical expectation, since the basis for making such calculations does not exist; and that it is our innate urge to activity which makes the wheels go round ...". He believed that little economic activity would occur without "... animal spirits-a spontaneous urge to action rather than inaction ..." (p. 161) and that if we were "... to depend on nothing but mathematical expectation, enterprise will fade and die ..." (p. 162).
} 
experiment inspired by Tenorio and Cason's (2002) study of the "Showcase Showdown" sessions of "The Price is Right" TV show. In our version of the optimal stopping game, two contestants compete over getting the highest score out of up to two spins of a wheel of fortune without going over a limit. Experimental subjects are real entrepreneurs, managers and employees and are all assigned the first player role. As in Tenorio and Cason (2002), people who have a tendency of spinning twice instead of once, all else equal, are viewed as being more actionoriented. Our hypothesis that entrepreneurs are more action-oriented than others can thus be tested by comparing entrepreneurs' tendency to spinning twice to employees and managers, while controlling for background characteristics in regressions including age, gender, education, income and the like.

This game offers interesting prospects with regards to the external validity of our experiment. Because not spinning leaves one ignorant about the counterfactual second spin, one feels as if blame can be evaded by opting not to spin. Not spinning then becomes the reference point, leading to a feeling that the score obtained on the first spin is lost every time the decision to spin results in going bust. Loss aversion will thus decrease spinning at the wheel. The game also interplays with curiosity in the following manner. Besides impacting one's total score, the decision to spin also provides information about the counterfactual second spin. That is, a curious person might spin simply to find out what might happen out of it.

We further test the propositions we derive from a simple theoretical framework that higher levels of action-orientedness are associated with higher curiosity and lower loss aversion by controlling for these two characteristics. For this purpose, individual loss aversion is measured by replicating an incentive-compatible multiple price list (MPL) elicitation procedure from Koudstaal et al. (2015) and individual curiosity is measured by employing the Curiosity and Exploration Inventory-II questionnaire in Kashdan et al. (2009).

Finally, the experiment includes, besides the baseline treatment, a counterfactual information treatment in which the potential role of loss aversion and curiosity as the mechanisms behind action-orientedness is changed in opposite ways, enabling to test which of the two mechanims is strongest. Half of the individuals are randomly assigned to this treatment, whereas the other half are assigned to the baseline treatment, thereby allowing a between-subject comparison. The counterfactual information treatment entails that the score of one's second spin is revealed regardless a subject's decision of spinning a second time (but it remains excluded from the total score of those not choosing to spin twice). As a result of this manipulation, a second spin may have a less positive effect on satisfying curiosity. If action-orientedness in the counterfactual information treatment is lower than in the baseline, this may be evidence of the role of curiosity. On the contrary, by changing the reference point from spinning once to spinning twice, a positive effect of changing the treatment on action-orientedness might be explained by loss aversion. Thus, the counterfactual information treatment provides an alternative way of testing the role of curiosity and loss aversion in explaining action-orientedness.

A large subject pool consisting of 1,441 professionals took part in the experiment. We show 
that entrepreneurs (who are more curious and less loss averse) spin the wheel a second time on higher scores of the first spin than managers and employees. This finding of a distinct playing strategy of entrepreneurs provides evidence that entrepreneurs are more action-oriented than others indeed. We also find that curiosity and loss aversion have the expected relationships with individuals' stopping strategies and controlling for these characteristics reduces the difference in the level of spinning between entrepreneurs and others to zero. In particular, curiosity has a significant impact on this reduction. This finding provides evidence that the underlying mechanism for differences in action-orientedness across occupations may be curiosity rather than loss aversion.

The results from the counterfactual information treatment show the same pattern: assignment to the treatment group leads to a decrease in the level of spinning. This difference between the treatment and the control group provides further evidence that the spin decision is driven by curiosity. Less expectedly, we find no evidence of a zero relationship between the individual measure of curiosity and action-orientedness for subjects assigned to the counterfactual information treatment. The theoretical framework in Section 3.3, based on Golman and Loewenstein (2015), shows that there are indeed circumstances under which the counterfactual information treatment would not alleviate individual curiosity, or might even strengthen it.

The results are largely in line with studies that dissociate entrepreneurship from inertia and indecisiveness based on a lower tendency to status quo bias than bankers (Burmeister and Schade, 2007) or executives (Dyer et al., 2008). Sandri et al. (2010) argue that entrepreneurs are not more prone to inertia than non-entrepreneurs in divestment decisions. Our study contributes to this literature by testing hypotheses we develop based on a simple theoretical model and employing a large scale incentive compatible experiment among professionals. We test differences in actionorientedness and we test predictions about how action-orientedness may be driven by curiosity and loss aversion.

This study highlights the importance of personality traits in predicting action-orientedness and is thus related to the general research program regarding the economic importance of noncognitive skills and personality traits (Borghans et al., 2008; Heckman et al., 2006). More specifically, the study links entrepreneurial action, and therefore an important phenomenon in relation to economic outcomes, to certain individual characteristics. To the extent that personality traits can be cultivated during early childhood, these findings have ramifications in how policy can nurture individuals that are entrepreneurially-minded.

The remainder of the paper is organized as follows. In Section 2 we discuss the conceptual background of the study: the psychology of (in)action, action-orientedness and occupational choice. Section 3 describes the game and presents formal models of how loss aversion and curiosity will affect play. In Section 4 we present the experimental design and procedures, including the sampling, a description of the game, the elicitation of behavioral traits, and the incentives used in the experiment. Results are presented in Section 5. Section 6 discusses the results and concludes. 


\section{Conceptual Background}

\subsection{The Psychology of Inaction}

Most people exhibit a preference for inaction when it is optimal to take action or when they should be indifferent between action and inaction (Samuelson and Zeckhauser, 1988; Spranca et al., 1991). Tendencies towards inaction are salient when the different options that the decision maker is facing can cause harm or when information about outcome probabilities is missing (Ritov and Baron, 1990; Frisch and Baron, 1988). In such settings, it can be observed that people judge harms that result from inactions as being less bad than harms that result from actions. Sometimes, people judge harms resulting from actions to be worse than even more harmful inactions (Baron and Ritov, 1994). Preferences for inaction are not always the norm. People can feel like inaction is worse when they are in position of responsibility or when it is not accepted as being "the right thing to do" (Ritov and Baron, 1990; Patt and Zeckhauser, 2000; Baron and Ritov, 2004; Tanner and Medin, 2004; Bar-Eli et al., 2007).

Causal discounting is a central mechanism behind preferences for inaction (Spranca et al., 1991). When harm occurs from inaction, believing that something other than our own decision is causing the outcome is more salient. This, in turn, leads to a smaller feeling of responsibility for harmful outcomes. When one takes action, however, the causal link between the harm and one's decision appears stronger. This account is consistent with norm theory which implies that people feel more regret when bad outcomes result from action rather than inaction because actions are more often seen as being "abnormal": it is easier to imagine abstaining from actions that where carried out than to imagine carrying out actions that were never performed (Kahneman and Tversky, 1982; Kahneman and Miller, 1986; Baron and Ritov, 2004). As a result of this illusion, reactions to harms resulting from actions are stronger.

Inaction can thus be viewed as being characteristic of those options that have a framing effect of allowing for the avoidance of blame (Baron and Ritov, 1994). Once inactions are set as reference points, good outcomes missed are seen as foregone gains whereas harms avoided would be seen as foregone losses (Ritov and Baron, 1990; Spranca et al., 1991). Given that losses weigh larger than gains when people are loss averse, inactions will be preferred over actions. In Section 3.2 a simple formal model is presented about the possible roles of reference dependent preferences and loss aversion for inaction.

While loss aversion can drive inaction, other mechanims may have the opposite effect and rather drive action-orientedness. Curiosity is one such mechanism since it has the effect of "killing regret" by leading individuals to search for information when the anticipation of regret would induce them to do otherwise (Van Dijk and Zeelenberg, 2007). Curiosity and regret are therefore opposing forces. An individual whose urge for knowing what would result out of action overcomes blame avoidance and will therefore take action. We hypothesize that more curious individuals are more action-oriented than others. In Section 3.3 a simple formal model is presented about 
the role of curiosity for action orientedness. ${ }^{2}$

\subsection{Links to Occupational Choice}

Entrepreneurs are less prone to engage in counterfactual thinking than managers and employees (Baron, 2000; Markman et al., 2002). As a result, they are expected to be less likely to feel regret for bad outcomes resulting from their decisions and thus less likely to seek the benefits of blame avoidance. Similarly, it can be found that entrepreneurs are more tolerant towards losses than managers and wage employees (Koudstaal et al., 2015). Given a greater tendency to undertake explorative search (Laureiro-Martínez et al., 2013), entrepreneurs are also more likely to be driven by curiosity. Compared to employees, managers should score higher on curiosity through their usually better scoring on positive affect (Seibert et al., 1999; Kashdan et al., 2004; Reio and Wiswell, 2000; Reio Jr and Callahan, 2004). One should therefore expect entrepreneurs to be more action-oriented than managers and employees. Table 1 summarizes the main behavioral traits associated with action-orientedness (derived from the formal models) and describes how individuals in different occupations are likely to score on these traits.

\section{Theoretical framework}

\subsection{The optimal stopping game}

We consider a simplified version of the showcase showdown game with only two players. Experimental subjects are all assigned the first player role; the second player role is played by the computer and subjects are informed about this. The players compete against the computer over getting the highest score out of up to two spins of a wheel of fortune, without going over a limit. In our experiment the wheel is divided into $N=9$ segments numbered from 1 to 9 . Each spin results in an equal chance of getting one of those nine numbers. Contestants play sequentially and can opt out of spinning a second time. It is the computer's turn after the first player has taken her decision whether or not to spin a second time (knowing the first player's total score). The total score for a contestant who chooses to spin twice equals the sum of scores on her two spins. For a contestant who spins only once the total score equals the score of her first (and only) spin. Going over $N=9$ results in immediate elimination from the game. In case of a draw, the first contestant wins by default. The latter tie-breaking rule deviates from the original version of the game, yet makes the rules easier for the participants and also simplifies the characterization of player 1's optimal strategy (see below).

The strategic situation for player 2 (the computer) is similar to the dealer role in blackjack. Its optimal strategy is simple: if player 1 eliminated herself by taking two spins, player 2 just spins once and wins for sure. If player 1 did not eliminate herself, let $T 1$ be her total score.

\footnotetext{
${ }^{2}$ The attribution of responsibility and norms about what one should do according to his or her role can also foster action-taking (Patt and Zeckhauser, 2000). For instance, it can be argued that medical doctors or goalkeepers have a bias for taking action rather than staying inactive (Bar-Eli et al., 2007).
} 
Player 2 should then take a second spin if and only if its first spin yields $T 1$ or less. Participants in our experiment are informed of this optimal strategy used by computer-player 2.

The optimal strategy for player 1 is more complicated. We fully characterize it for any positive integer $N$. Let $t$ denote the outcome of player 1 's first spin and $p_{1}(t)$ her probability of winning if she stops after her first spin (such that her total score equals $t$ ). Similarly so, let $p_{2}(t)$ denote the probability of winning if player 1 takes a second spin. Clearly, the optimal strategy for player 1 is then to spin again iff:

$$
p_{2}(t) \geq p_{1}(t)
$$

Now, based on Coe and Butterworth (1995), it can be derived that (see Appendix A.1):

$$
\begin{aligned}
& p_{1}(t)=\frac{t^{2}}{N^{2}} \\
& p_{2}(t)=\frac{1}{N^{3}}\left[\frac{N(N+1)(2 N+1)}{6}-\frac{t(t+1)(2 t+1)}{6}\right]
\end{aligned}
$$

Intuitively, $p_{1}(t)$ is increasing in the outcome of the first spin $t$ while $p_{2}(t)$ is decreasing (see Figure 1). Roughly speaking $t$ can fall within three different ranges. First, it can be that low that it is rather obvious that player 1 should take a second spin. Second, it may be that high that it is clear that player 1 should not take a second spin. Third, $t$ can be intermediate, such that it is unclear at first sight whether or not player 1 should take a second spin. Only the intermediate range is likely to yield insights about subjects' action-orientedness; for the 'obvious' extreme cases we will most likely find (too) little variation. With this in mind we have chosen the value of $N$ as to maximize the relative size of this intermediate range, while at the same time keeping $N$ as small as possible for simplicity reasons. With our choice of $N=9$ the intermediate range arguably corresponds to $t \in\{3,4,5,6\}$, where for $t=5$ we have that $p_{2}(t) \approx p_{1}(t) \approx 0.31$.

In the experiment we elicited subjects' strategies of playing the wheel game. Here a strategy corresponds to a switching point $\omega \in\{0,1,2, \ldots, 9\}$, such that the participant spins a second time if and only if $t \leq \omega$. As derived above the optimal strategy specifies $\omega^{*}=5$. Using this strategy, a participant wins in $51.67 \%$ of the cases. Note though that employing a suboptimal strategy does not necessarily lead to worse performance. This depends on the outcome of the first spin $t$. For instance, if a participant would never spin twice no matter what the score of her first spin is, i.e. her switching point equals $\omega=0$, she actually still plays optimal for all $t \geq 6$. Only for $t \leq 5$ her choice (of not spinning) is suboptimal and in expectation leads to lower performance. With this extreme strategy player 1 still wins with probability $\frac{1}{9} \cdot \sum_{t=1}^{9} p_{1}(t)$, which corresponds to $39.09 \%$ of the cases. Figure 3 depicts the expected likelihood of winning for all strategies $\omega \in\{0,1,2, \ldots, 9\}$ at the wheel. ${ }^{3}$ Differences in the percentage of wins are indeed small in the intermediate range $\omega \in\{3,4,5,6\}$.

\footnotetext{
${ }^{3}$ For a switching point equal to $\omega$ the expected likelyhood of winning equals 100 . $\left(\frac{1}{N} \cdot \sum_{t=1}^{\omega} p_{2}(t)+\frac{1}{N} \cdot \sum_{t=\omega+1}^{N} p_{1}(t)\right) \%$.
} 


\subsection{Loss aversion}

The optimal stopping strategy of player 1 as characterized in (1) may change if she is loss averse. We formally model loss aversion by means of reference dependent preferences. Let $x \in\{0, X\}$ denote the monetary payoffs from the choice made, with $x=0$ after losing the game and $x=X$ in case player 1 wins. Moreover, let $r$ be player 1's reference point in terms of monetary payoffs. Following Köszegi and Rabin (2006) and Köszegi (2014), we assume that utility takes the following form:

$$
u(x \mid r)= \begin{cases}x+\eta(x-r) & \text { if } x \geq r \\ x+\eta \lambda(x-r) & \text { if } x<r\end{cases}
$$

The first term gives standard monetary payoffs while the second term reflects gain-loss utility relative to the reference point. Parameter $\eta \geq 0$ is the weight on gain-loss utility and $\lambda \geq 1$ captures loss aversion, i.e. the notion that losses are more painful than same-sized gains are pleasant. Key in any model of reference dependent preferences is defining the reference point $r$. In our application, we let $r$ correspond to the payoffs player 1 would have obtained by taking reference action $R$ and assume that $R$ varies with the treatment.

In particular, following the literature on resolution feedback, a logical reference point in the baseline treatment is what would have happened if player 1 would have spun only once. That is, the 'ommission' is taken as the reference action. If player 1 stops after the first spin, she has no information on what would have happened had she taken a second spin. Yet if she does spin twice, player 1 obviously learns her would be total score if she would have spun only once, and thus has almost complete knowledge about what would have been the outcome then. ${ }^{4}$

If the reference action equals $R=S t o p$ for both choice options (i.e. stop and spin twice) alike, it can be derived that taking a second spin is preferred whenever (cf. Appendix A.2) :

$$
p_{2}(t) \geq p_{1}(t)+\frac{\left(1-p_{1}(t)\right) \cdot(\lambda-1) \eta \cdot p_{1}^{2 \operatorname{Loss}}(t)}{1+\eta+(\lambda-1) \eta \cdot p_{1}^{2 \operatorname{Loss}}(t)}
$$

Here $p_{1}^{2 \text { Loss }}(t)$ denotes the ex ante conditional expectation of the probability that, given that spinning twice led to a loss for player 1 , spinning only once would have given her a win. ${ }^{5}$ Intuitively, with 'Stop' as the reference action, loss aversion kicks in whenever player 1 would have won after one spin, but lost after actually taking a second spin. The more player 1 ex ante anticipates experiencing such a loss, the less likely she is to take a second spin. For $\eta=0$ or $\lambda=1$ condition (2) reduces to the standard governing inequality (1). Otherwise it is more stringent, as the second term on the r.h.s. is necessarily positive. Thus, as observed by Baron and Ritov (1994, p. 479), assuming the omission to be the reference point in itself cannot explain an omission bias, but together with loss aversion $(\lambda>1)$ it can.

\footnotetext{
${ }^{4}$ Only if player 1 goes over $N$ by spinning twice she does not observe the computer's second spin $c_{2}$ and thus has no perfect knowledge about what would have happened in case the computer's first spin is weakly below player one's first spin, i.e. $c_{1} \leq t$. We assume that in these instances player 1 takes ex ante expectations over $c_{2}$.

${ }^{5}$ In Appendix A.2 it is shown that $p_{1}^{2 \operatorname{Loss}}(t)=p_{1}(t) \cdot \frac{t}{N}$, thereby fully characterizing inequality (2).
} 
Given that in the counterfactual information treatment player 1 always learns the outcome of the second spin irrespective of whether or not it is actually taken, a logical reference action there is $R=\operatorname{Spin}$ (again after both choice options alike). In that case, she is predicted to take a second spin iff:

$$
p_{2}(t) \geq p_{1}(t)-\frac{\left(1-p_{1}(t)\right) \cdot(\lambda-1) \eta \cdot p_{2}^{1 \text { Loss }}(t)}{1+\eta}
$$

In this case player 1 experiences a loss if her actual choice to stop led to a loss, while taking a second spin would have given her a win. $p_{2}^{1 \text { Loss }}(t)$ denotes the (ex ante) conditional expectation of the probability that this happens. ${ }^{6}$ Intuitively, with $R=$ Spin as the reference action, a loss is potentially only felt after spinning once. This makes it more likely that player 1 takes a second spin.

The r.h.s. in (3) is necessarily smaller than the r.h.s. in (2). Loss aversion thus predicts that player 1 is more likely to take a second spin in the counterfactual information treatment than in the baseline treatment. Moreover, as the r.h.s. in (2) increases with $\lambda$, stopping becomes relatively more attractive in the baseline treatment when $\lambda$ increases. People who are more loss averse thus should be less likely to spin twice in the baseline treatment than people who are less loss averse. The opposite applies in the counterfactual information treatment. There more loss averse people are more likely to take a second spin compared to less loss averse people.

Arguably, given that one can always form realistic beliefs about what would have happened if the other option were taken, another logical reference point in the counterfactual information treatment might be 'the road not taken'. That is, $R=$ Stop in case one chooses to spin and $R=$ Spin if one chooses to stop. As shown in Appendix A.2, this leads to the exact same comparative statics predictions as discussed here.

\subsection{Curiosity}

An alternative reason why player 1 may want to deviate from strategy (1) is curiosity. Intuitively, if player 1 is curious per se about the outcome of the second spin, all else equal this makes taking a second spin more attractive to her. Following Golman and Loewenstein (2015) we formalize this straightforward intuition by modelling curiosity as a preference for clarity about the activated question: 'What is the outcome of the second spin?'. For a question with $N$ possible answers, clarity in their theory is captured by the inverse measure of entropy $\sum_{i=1}^{N} \pi_{i} \ln \left(\pi_{i}\right)$, where $\pi_{i}$ is the probability that answer $i$ is correct. The lower this necessarily non-positive term is, the less clear one is ex ante about what the correct answer to the question at hand is. In our application, if player 1 does not learn the outcome of the second spin, all $N$ outcomes are equally likely to her and $\pi_{i}=\frac{1}{N}$. In that case clarity equals its minimum value of $\sum_{i=1}^{N} \frac{1}{N} \ln \left(\frac{1}{N}\right)=-\ln (N)$. Yet if player 1 does learn the outcome of the second spin, clarity increases to its maximum value

\footnotetext{
${ }^{6}$ In Appendix A.2 it is shown that $p_{2}^{1 \text { Loss }}(t)=\frac{p_{2}(t)-p_{1}(t) \cdot\left(1-\frac{t}{N}\right)}{\left(1-p_{1}(t)\right)}$.
} 
of zero. ${ }^{7}$

Let $w_{s} \geq 0$ reflect the preference intensity for clarity about the second spin $s$. The larger $w_{s}$ is, the more curious player 1 is about the outcome of the second spin. The governing inequality in the baseline treatment then becomes:

$$
\begin{aligned}
p_{2}(t) \cdot X+w_{s} \cdot 0 & \geq p_{1}(t) \cdot X+w_{s} \cdot(-\ln (N)) \\
& \Longleftrightarrow p_{1}(t)-w_{s} \cdot \frac{\ln (N)}{X}
\end{aligned}
$$

Obviously, (4) is less stringent than (1). Moreover, as the r.h.s. of (4) decreases with $w_{s}$, more curious people are more likely to take a second spin.

Since in the counterfactual information treatment player 1 learns the outcome of the second spin anyway, the governing inequality there simply reduces to (1). Opposite to loss aversion, curiosity thus predicts that player 1 is less likely to take a second spin in the counterfactual information treatment than in the baseline treatment. Moreover, in the baseline treatment more curious people are more likely to take a second spin while curiosity does not play a role in the counterfactual information treatment.

Unexpectedly, our empirical results reveal that curiosity does play a role in the counterfactual information treatment: even when becoming always informed about the outcome of the second spin, more curious people are more likely to take a second spin. A potential explanation for this can also be found within the Golman and Loewenstein (2015) framework. In brief the underlying idea is that, with curiosity about the second spin now always being satisfied, attention shifts towards the question: 'Who wins the game?' Taking a second spin on average increases clarity regarding this question, as it either makes it more likely that player 1's total score goes over $N$ (leading to a sure loss), or it increases player 1's winning chances. Under such an induced shift in attention due to resolution feedback, it is still predicted that spinning occurs more often in the baseline treatment, but now in both treatments more curious people are predicted to spin more. As we did not a priori anticipate a role for curiosity in the counterfactual information treatment, and because the formulas become somewhat more involved, we relegate the discussion of this extension of the above theory to Appendix A.3.

\section{Experimental Design and Procedures}

Our method consists in having participants from different occupations play various sessions of the optimal stopping game. The experiment is conducted online using the Qualtrics platform and consists of four phases in total. In the first phase, participants are prompted with background questions. Background characteristics administered are age, gender, highest level of education

\footnotetext{
${ }^{7}$ Formally, we then have $(N-1) \cdot(0 \cdot \ln (0))+1 \cdot(1 \cdot \ln (1))=0$; for $(N-1)$ potential values of $s$ one knows for sure that $s$ does not take this value, for one potential value one knows for sure that $s$ does take this value. (Here $0 \ln 0=0$ by convention, as $\lim _{x \downarrow 0} x \ln x=0$.)
} 
and income for the last year in brackets. The second phase is the central part of the experiment. After two practice rounds, participants are randomly assigned to one of our two treatments, either baseline or counterfactual, with equal probability. Participants' playing strategies -or more precise, switching points at the wheel- are then elicited using a strategy method. The switching point serves as a measure of the participant's level of action-orientedness. In the third phase, participants answer psychological questionnaires measuring their level of curiosity. Finally, in the fourth phase, yet another strategy method is undertaken for eliciting levels of loss aversion in an incentive compatible fashion.

This design allows answering our research question using two distinct approaches. First, we can test whether entrepreneurs are more action-oriented than others when controlling for background characteristics. Given that spinning can be framed as taking action, we view higher levels of spinning to be equivalent to higher levels of action-orientedness. We can also test the role of the underlying mechanisms of loss aversion and curiosity in this approach by including the individual measures of these characteristics as independent variables in these regressions.

For the second approach, the experiment includes, besides the baseline treatment, a counterfactual information treatment in which the potential role of loss aversion and curiosity as the mechanisms behind action-orientedness are changed. In the counterfactual information treatment the score of one's second spin is revealed regardless of one's decision of spinning a second time. As a result of this manipulation, a second spin may have a less positive effect on satisfying curiosity. Hence, if action-orientedness in the counterfactual information treatment is lower than in the baseline, this may be because of the declined impact of curiosity. On the contrary, in effect changing the reference point from spinning once to spinning twice, a positive effect of changing the treatment on action-orientedness might be explained by loss aversion. The counterfactual information treatment provides an alternative way of testing the roles of curiosity and loss aversion in explaining action-orientedness.

\subsection{Sampling}

Invitations were sent out per email on December 7, 2015 requesting responses to the survey questions and to play the games online. The invitations were sent to a large sample of Dutch entrepreneurs, managers and employees who were reached through the Amsterdam Center for Entrepreneurship (ACE), "De Baak" training center and a market research agency respectively. All invitees had 14 days to respond, and non-respondents received a reminder after seven days. To not overburden the participants, each session (including playing the game and answering survey questions) is designed to last approximately 15 minutes. Appendix B shows the details.

1,441 respondents completed the survey up to the second phase and 1,345 respondents, i.e., $93 \%$ completed the entire survey ${ }^{8}$ before the deadline on December 21 . The median response time was 13 minutes. $729(50.59 \%)$ of those participants were randomly assigned to the baseline

\footnotetext{
${ }^{8} 1,345$ respondents (more than $93 \%$ of those who completed the second phase) completed all four phases of the questionnaire. We therefore believe that attrition is negligible.
} 
treatment. Participants assigned to different treatments do not differ in their background characteristics (age, gender, education and income) indicating that the assignment process balanced out different demographic groups in a proper random way. Out of the 1,441 respondents, 777 qualify as being employees, 424 are entrepreneurs and 179 are managers. 32 respondents declared that they were unemployed while 29 did not fall in any of the other four categories. The remainder of the analysis will focus on those participants that fall within the three occupations of our interest. The descriptive statistics of background variables such as gender, age and education show that the sample is composed similarly as the earlier samples used by Koudstaal et al. (2015), who assess the representativeness of their sample as being good (as far as their data allow them to test this). In the final analyses, we will limit the sample to 1,057 observations in total (594 employees, 322 entrepreneurs and 141 managers) due to the exclusion of outliers in the sense that the stopping decision is outside the reasonable range of $\{3,4,5,6\}$, see Section 4.1 .

\subsection{Incentives}

Everything about the payoff and payout rules is transparently communicated in the experiment. Given budget restrictions and the rather high average income levels of the population studied, we chose to pay out a substantial amount to only a few randomly selected participants (Gneezy and Rustichini, 2000; Laury, 2006; Koudstaal et al., 2015). To foster trust, the selection of prize winners and all random draws in the experiments were assigned to a civil-law notary who also monitored a legitimate course of the payouts. Twenty participants are randomly selected to actually receive their earnings. Participants are aware that this means a payout chance of one percent, based on participation rates in previous waves of the experiment. Ex post, the payout rate was around two percent because the sample turned out smaller than in previous waves of the experiment. For those selected, payoffs will depend on their decisions in the second and fourth phase of the game. A flat payoff of $€ 350$ for answering the unincentivized questions in phases 1 and 3 is added to this.

Regarding phase two ("Showcase Showdown"), participants are informed that their switching point will be used to determine the spinning decision of a random game against the notary who will play exactly like the computerized player 2 . In case of winning the match, the participant is awarded with $€ 100$ and zero otherwise for this phase of the experiment.

Regarding phase four (loss aversion), one out of the eight decisions from the Multiple Price List is randomly selected for payout. The participant's loss aversion score is used to determine whether she prefers the safe or the other option. In case of the safe option her earnings in this phase are zero. In case of the risky option, the participants' payoffs will vary between winning $€ 300$ and losing $€ 350$. 


\subsection{Definitions and Measurement of Behavioral Characteristics}

\subsubsection{Loss aversion}

The loss aversion account of inaction can be linked to a fear of losing whatever score one is endowed with. An interesting feature of the baseline game is that not spinning in the second round can be framed as not acting, for three main reasons. First, since players remain ignorant about the outcome of the second spin when not spinning twice, not spinning creates the illusion of avoiding responsibility and blame. Second, not spinning will result in having the same score one has obtained in the first spin. Not spinning can thus be linked to a "metastatic" mode of control (Kuhl, 1985) and be seen as not doing anything. Third, not spinning offers the benefit of losing by being outscored rather than going bust, which can be viewed as the "normal" or the "right" thing to do. From a reference point perspective, not spinning would lead to seeing an eventual improvement of one's score through spinning as a foregone gain and elimination through spinning as a loss. In the counterfactual information treatment, however, the reference point is shifted towards spinning twice. Hence, comparing stopping decisions across the baseline and counterfactual information treatments can be informative about the role that loss aversion might play.

We replicate Koudstaal et al. (2015)'s incentivized measurement of loss aversion comparing entrepreneurs, managers and employees. It comes down to measuring loss aversion by means of the MPL applied by Fehr and Goette (2007) and Gaechter et al. (2010), which in essence is like the Holt and Laury (2002) price list but also includes negative payoffs. Eight decisions are presented to participants, each consisting of a choice between a sure and a risky gamble, where the risky gamble can also lead to a loss. The sure bet involves a gain of $€ 0$, while the risky gamble involves a $50 \%$ chance of winning $€ 300$ or losing an amount $x$ that varies from $€ 0$ to $€ 350$ in each decision. Participants are asked to indicate the option for which they are indifferent between the sure and the risky gamble by going through a strategy method. A benefit of the Gaechter et al. (2010) measure is that it is significantly correlated with loss aversion in riskless choices. As such it strongly alleviates the potential issue that loss aversion might be confounded with risk aversion (Gaechter et al., 2010; Kahneman et al., 1990). Appendix B.3 provides a snapshot of the decisions provided to the participants.

\subsubsection{Curiosity}

As discussed in Section 3.3, curiosity can potentially drive action-orientedness. Comparing spin decisions in the baseline to the counterfactual information treatment allows measuring whether curiosity plays a role. Moreover, we survey participants with personality questionnaires in order to elicit their level of curiosity. The curiosity and exploration inventory-II questionnaire proposed by Kashdan et al. (2009) consists of 10 Likert scale items. The questionnaire is an extension to an earlier popular measure of the individual quest for novelty and challenge (Kashdan et al., 2004). The 10 items are presented in Appendix B.2. 


\subsubsection{Other behavioral characteristics}

When linking the spin decision with occupational choice, several behavioral characteristics can come to one's mind, besides loss aversion and curiosity, that might explain action-orientedness. Risk aversion and overconfidence would be prominent ones. In the context of our study, these traits are not taken into account. There are both theoretical and empirical reasons for this. For one thing, risk aversion, as defined by standard theory, does not come into play in the optimal stopping game. ${ }^{9}$ As for overconfidence, one should not expect any difference between the the two treatments in the way people play at the wheel. Overconfidence can drive more spinning in both. Overconfident people might think being more likely to obtain a favorable score on their second spin by overweighing scores that will lead to an improvement of the total score and underweighing scores that will lead to going bust. A 'by-product' of having such beliefs is the over-sampling of the wheel, independent of whether counterfactual information is provided, contrary to the case of curiosity. ${ }^{10}$ As we will see, this particular trait cannot explain our results. Furthermore, empirical findings in experimental settings do not provide support for the idea that there are differences between entrepreneurs and others in terms of risk aversion and overconfidence. As a result, we cannot expect these traits to explain any difference between entrepreneurs and others in terms of their action-orientedness.

\subsection{Definitions of Entrepreneurs, Managers and Employees}

Measuring differences between entrepreneurs and others involves two complex judgmental decisions. The first is the definition of entrepreneurs. The second is the definition of 'others'. Consistent with Koudstaal et al. (2015), the qualifying characteristics for inclusion in the entrepreneur sample are: people who have founded, inherited or taken over a company (within 5 years after startup) they are currently (co-)managing. Because we use a large and diverse sample of entrepreneurs, we can later use more specific definitions of entrepreneurship and test whether that matters. A stricter definition of entrepreneurs aims at mimicing a sample of more 'Schumpeterian' entrepreneurs. The stricter measure we will use is entrepreneurs with above median incomes. Moreover, we are interested in the difference between entrepreneurs and others when defining entrepreneurs as the people owning and managing firms in the start-up phase, i.e. younger than 5 years old. Entrepreneurs can also be distinguished based on whether they are sole prorpietors or owners of an incorporated business, the latter group often being associated with more successful entrepreneurs (Levine and Rubinstein, 2013). As a final subgroup of entrepreneurs viewed more successful, we consider entrepreneurs with above median numbers of

\footnotetext{
${ }^{9}$ To illustrate this formally, let $u(x)$ be a general utility function, with $u^{\prime}(x)>0$ for all $x$. Risk aversion is then captured by utility curvature, i.e. how $-u^{\prime \prime}(x)$ compares relative to $u^{\prime}(x)$. In our game with only two monetary outcomes $(x=0$ and $x=X)$, utility curvature does not play a role: the utility of action $a$ with win probability $p_{a}$ then equals $u(0)+p_{a} \cdot(u(X)-u(0))$, so one should always choose the action with the highest win probability $p_{a}$ irrespective of how $u(x)$ looks like.

10 A similar reasoning applies to players driven by "illusion of control", another behavioral trait that might lead to more spinning but to the same extent in both treatments.
} 
direct reports.

The definition of 'others' (see also Koudstaal et al. (2015) for a discussion) is challenging too. Actually one would like a control group that is very similar to the group of entrepreneurs but different from them in only one respect: they are not entrepreneurs. Koudstaal et al. (2015) argue that a close as possible to ideal control group is a group of managers: they usually have the same age and education distribution and they do not differ by much in their daily responsibilities and activities from entrepreneurs (other than the responsibilities and activities associated with the pure act of entrepreneurship). Therefore, managers are the first control group. In our study, we define managers as those who are employed by an organization they did not start up themselves and have at least two subordinates with direct responsibility.

A second control group should make a comparison possible to most of the previous studies that compare entrepreneurs to 'others'. These studies have usually employed as control groups employees (Hartog et al., 2010; Van Praag et al., 2013; Shyti and Paraschiv, 2014) or the population at large (Holm et al., 2013). We use a sample of employees. We measure 'employees' as people who are employed by an organization and do not belong to the first two groups. ${ }^{11}$

\section{Results}

\subsection{Distribution of Action-Orientedness and Descriptives}

Figure 2 shows the distribution of action-orientedness $\omega$ under the baseline and the counterfactual information treatments. As we can see, $\omega \in\{3,4,5,6\}$ for most participants. Moreover, the same patterns of play can be observed across all occupations in this range of action-orientedness: the share of $6 \mathrm{~s}$ is greater than the share of $4 \mathrm{~s}$ for the three occupations. For example, there are almost twice as many employees that would stop spinning on a 6 than on a 4 under the baseline treatment. But this difference between the share of those with $\omega \in\{4,6\}$ balances out and gets much closer under the counterfactual information treatment. This pattern of a decreasing gap between the share of $6 \mathrm{~s}$ and $4 \mathrm{~s}$ in the counterfactual information treatment is observed across all three occupations. Although any level of action-orientedness could represent genuine preferences, we only consider the middle range of $\{3,4,5,6\}$ as the range of switching decisions for analysis.

During the strategy elicitation session, we used the bisection method. In other words, players were first asked whether they would spin again if they get a score of 2 on their first spin. If they answer by the affirmative, they are prompted about whether they would do the same for a score of 8 . If a participant answers this question with the affirmative by mistake, then the next question concerns a first spin score of 9 in which case the switching point will be extreme. Therefore, extreme levels of action-orientedness could be due to mistakes because participants did not have the possibility to go back to their earlier decisions in case they realized that they had made a mistake. Outliers are not over-represented in a particular profession or treatment

\footnotetext{
${ }^{11}$ Participants who are both entrepreneurs and managers or employees, and therefore eligible for multiple subsamples, were instructed to select the category in which they generate most of their income.
} 
(baseline or counterfactual). Table 9 in Appendix $\mathrm{C}$ shows that our findings are robust to the inclusion of outliers. Table 10 in the same Appendix shows the results from a Probit analysis where observations from outside the middle range of switching points $\{3,4,5,6\}$ take on a value of one for the dependent variables and the other, less extreme, observations take on a value zero. Indeed, neither specific occupations nor specific treatments are non-randomly distributed across these groups. However, people with higher levels of education are under-represented in the group that chose 'outliers' as their stopping levels, which is consistent with the idea that these respondents are mistaken for one reason or the other. The remainder of the analyses are based on this smaller sample of 1,057 observations where the switching point lies in the $\{3,4,5,6\}$-range.

Table 2 summarizes the background variables across occupations, where $\omega \in\{3,4,5,6\}$. Consistent with empirical regularities, there is a smaller representation of females in entrepreneurial and managerial occupations, whereas males are even more over-represented in the group of entrepreneurs. The distribution of educational attainments across occupations is also consistent with previous findings. Reflecting common features of the labor market, our samples of entrepreneurs and managers are older than our sample of employees, whereas entrepreneurs are also older than managers. Employees are mostly represented by participants having a vocational degree, entrepreneurs are most likely to have a college degree and managers have obtained either a college or a university degree. Kolmogorov-Smirnov tests indicate that the difference in the distribution of educations attainment is significant between employees and the other two occupations. Regarding income, our sample is also consistent with empirical regularities where employees have a right-skewed income distribution, entrepreneurs have the most dispersed income distribution and managers have higher average income levels. Kolmogorov-Smirnov tests show that all three occupations significantly differ in the distribution of their income levels.

Panel A of Table 3 summarizes the behavioral variables for the sample of $n=1,057$ with 'reasonable' levels of action-orientedness. The first three columns show means per occupation, whereas the last one shows the means for the entire sample. The averages across treatment variations are shown in the rows. As expected, entrepreneurs score highest on action-orientedness, and curiosity and lowest on loss aversion. The differences in action-orientedness between the treatments are significant. Subjects are more likely to opt for a second spin in the baseline treatment than in the counterfactual information treatment. This suggests, according to our theoretical predictions, that curiosity triumphs over loss aversion in the explanation of actionorientedness. Because we observe a change in the way subjects play, this result also suggest that the spin decision is not driven by overconfidence. However, we will only draw firm conclusions once we have used a multiple regression framework to explain action-orientedness.

Panel B in table 3 establishes that the various behavioral characteristics are correlated in the expected ways: Action-orientedness is negatively correlated with loss aversion, whereas loss-aversion and curiosity show a negative correlation. The raw correlation between actionorientedness and curiosity is positive, as expected. However, it is low and insignificant.

Table 4 shows the descriptive statistics of the stricter definitions of entrepreneurs. As we can 
see, close to three quarters of entrepreneurs own companies that have survived the first 5 years. Also, a third of the entrepreneurs in our sample have incorporated their business whereas more than half of them are sole proprietors. Finally, more than $40 \%$ of entrepreneurs have more than 10 direct reports. In line with our intentions, these characteristics seem to indicate that we have over-sampled more successful entrepreneurs.

\subsection{Action-Orientedness and Entrepreneurship}

We now proceed with testing whether entrepreneurs are more action-oriented than managers and employees in a regression framework. The results are shown in table 5. The dependent variable is action-orientedness measured in terms of the switching point at which a respondent (still) decides to spin a second time.

First, we establish whether there is a direct relationship between occupational categories and action-orientedness. In Model 1, we regress action-orientedness on occupational categories while controlling for background characteristics (age, gender, education and income). The results show that managers and employees are less action-oriented than entrepreneurs. Second, we gradually add the behavioral characteristics of interest to the specification of the previous model. In Model 2, we add loss aversion as a control. This characteristic is significantly related to actionorientedness and renders the difference between entrepreneurs and managers less significant. By controlling for curiosity (Model 3), we find that the difference between entrepreneurs and others is no longer significant. In Model 4, we add both behavioral characteristics to the specification and find that each has a distinctive association with action-orientedness. Unsurprising, and consistent with the result described above and earlier findings, we show in Table 6 indeed that entrepreneurs are they are less loss averse than employees (Model 1) and more curious than both managers and workers (Model 2). These models regress loss aversion and curiosity respectively on occupations while controlling for background characteristics. All in all, the results are consistent with the idea that entrepreneurs are more action-oriented than others and that this difference is (partly) associated with a difference in curiosity and, to a lesser extent, loss aversion.

We have further tested whether the above results differ when using stricter defintions of entrepreneurship. The results are shown in Table 7. Models in this table show the results of our main regression (c.f. Model 1 in Table 5) when we split the sample of entrepreneurs in terms of company age (lower or higher than 5 years), income (below or above the median, legal structure (sole proprietorship versus incorporated), and number of direct reports (at most 10 or more). Most of the differences between entrepreneurs and others seem to be associated with the younger, smaller and less successful group of entrepreneurs. For instance, a significant difference can be found between entrepreneurs of companies younger than 5 years and others (Model 1), whereas the difference is not significant when considering entrepreneurs whose companies have lived for more than 5 years (Model 2). However, we do not find that the difference in the differences of action-orientedness between young-firm-owning entrepreneurs versus others and old-firm-owning entrepreneurs versus others is statistically signifcant. Furthermore, the difference between en- 
trepreneurs and others when the definition of entrepreneurs is based on those with higher incomes is not different from what we found earlier (Models 3 and 4). While there is evidence that sole proprietors are more likely than incorporated entrepreneurs to differ from others (Models 5 and 6 ), the difference between sole proprietors versus others and incorporated entrerpeneurs versus others is not significant. We also find that the difference between entrepreneurs and others is more likely to be driven by entrepreneurs with 10 or less employees (Models 7 and 8). Once again, this difference turns out to be insignificant. In sum, the evidence when comparing stricter definition of entrepreneurs with others does not support the idea that more successful entrepreneurs (i.e. those with older firms, who are incorporated, or with more employees) are more action-oriented than others. In fact, the opposite is more likely to be (weakly) true.

\subsection{Action-Orientedness, Curiosity and Loss-Aversion: Counterfac- tual Information Treatment}

Our counterfactual information treatment is intended to intervene at the level of referencedependent preferences and curiosity. Table 5 shows that the counterfactual information treatment has a negative impact on action-orientedness. Because giving information about the (would be) outcome of the second spin reduces the likelihood of spinning, we conclude that curiosity has a stronger relationship with action-orientedness than loss-aversion (the latter would lead to increased action-orientedness in the counterfactual information treatment). This conclusion is consistent with our conclusions based on the finding that the association between actionorientedness and entrepreneurship vanishes, once we control for one's individual level of curiosity.

If different mechanisms drive the stop decision across occupations, then one should expect to find an interaction between the assignment to the counterfactual information treatment and occupation. If only a treatment (but no interaction) effect is found, then this would be evidence that the same mechanism drives action-orientedness across all occupations. To test for this, we run the same set of hierarchical regressions with the addition of interaction effects for the treatment and occupational categories. The results are shown in table 8. The interactions between occupational categories and the counterfactual information treatment (c.f. Model 1) turn out to be insignificant. In other words, the overall effect of the treatment is homogeneous across occupations, suggesting that the same mechanism drives action-orientedness across occupations.

Models 2-4 analyze the association between the counterfactual information treatment on the one hand, and loss aversion and curiosity on the other. We would expect that the counterfactual information treatment decreases the association between action-orientedness and curiosity whereas it would increase the association between action-orientedness and loss aversion. Contrary to our predictions (c.f. Section 3.2), Model 2 shows that the effect of loss aversion is marginally stronger under the counterfactual information treatment. Model 3 shows that the effects of curiosity is not weaker, but marginally stronger under that counterfactual information treatment. The theoretical framework in Section 3.3, based on Golman and Loewenstein (2015), shows that there are indeed circumstances under which the counterfactual information treatment would not 
alleviate curiosity, and might even strengthen it. The intuition behind this result from formal theory is as follows. The lack of information in the baseline treatment might cause a focus on the desire to know the outcome of the second spin and thereby, myopically, remove any curiosity about the remainder of the game. As soon as information is obtained about the outcome of the second spin, the cause of myopia is removed and the focus of a subject's curiosity is on wanting to know as soon as possible whether or not she wins the game. This knowledge is obtained sooner by spinning twice because it increases the probability of obtaining high overall scores, including 9 , as well as the probability of going over it. The former leads to more clarity that a win is likely (and for an overall score of 9, clarity of a sure win), while the latter leads to immediate knowledge that the game is lost. Therefore, also in the counterfactual information treatment, higher levels of curiosity might lead to a higher likelihood of spinning twice. Theoretically, the assocation between curiosity and spinning twice might even be stronger in the counterfactual information treatment than in the baseline treatment.

\section{Discussion and Conclusion}

By analyzing the optimal stopping strategies of a large sample of professionals in an incentive compatible setting, we provide evidence that entrepreneurs are more action-oriented than managers and employees. This novel finding is consistent with common wisdom and theoretical predictions. The finding is furthermore in line with earlier empirical findings on related characteristics: entrepreneurs have also been found to have a lower status quo bias than managers. Furthermore, we predict - based on theoretical models as well as theoretical reasoning - that action-orientedness is associated with loss aversion (negatively) and with curiosity (positively). Moreover, as we demonstrate, like others did before, entrepreneurs have lower levels of loss aversion and higher levels of curiosity. Given all of this, the question arises: Could the higher action-orientedness of entrepreneurs be explained by their higher level of curiosity and their lower degree of loss aversion?

We find evidence that the curiosity of entrepreneurs is indeed an important factor for the explanation of their higher levels of action-orientedness than others. The higher willingness of entrepreneurs to take action seems not to be related to reference-dependent preferences or their lower level of loss aversion. Moreover, alternative explanatory mechanisms such as risk aversion and overconfidence are also unlikely to cause the higher levels of action-orientedness among entrepreneurs, all else equal. Curiosity is the only control variable taking away the association between entrepreneurship and action-orientedness, whereas the differences between the main and counterfactual treatments point strongly into the same direction (while providing evidence against other potential explanations).

Action-orientedness, however, is unlikely to be positively associated with entrepreneurial success, based on our analyses of heterogeneous treatment effects. Our results indicate that entrepreneurs who score higher on various performance indicators are not more action-oriented 
than those who score lower. On the contrary, the difference between entrepreneurs and others is most likely to be driven by subgroups of entrepreneurs having younger firms, with fewer direct reports, and who act as sole proprietors instead of owner-managers of incorporared businesses. Action-orientedness is therefore unlikely to be associated with high growth entrepreneurship.

Some limitations pertain to our study. As always there is a tradeoff between internal and external validity. In experimental settings, internal validity comes often at the cost of external validity. In this case, the internal validity may also be questioned, to some extent. For instance, we expected the counterfactual information treatment to diminish the role of curiosity on average, as we expected. However, in fact the counterfactual information treatment might still trigger curiosity. According to the theoretical model and our empirical results, people with higher curiosity levels who experience the counterfactual information treatment are marginally more inclined to spin twice (and not stop). However, this does not compromise our main results.

The fact that the experiment has been executed online can be viewed as another limitation regarding the internal validity of the study because it limits the control over the subjects in the experiment. Of course, the online experiment was necessary to obtain such large samples of professionals. The fact that professionals instead of students participated in the experiment might increase the external validity of the study. Moreover, regarding the external validity of our study, it is worthwhile pointing out that action-orientedness as measured in our experimental setting could be viewed in analogy to the entry decision. For instance, a person who is willing to start up a new venture might have to leave wage-employment. In this setting, if staying as a wage-employee is viewed as inaction, then the benefits of this option (the steady salary) can be viewed as a loss compared to the gains of the income and utility resulting from entrepreneurship (which will be framed as action). This framing effect of starting up new ventures as taking action can render the option less attractive for loss averse people, from a reference-dependent preferences perspective and more attractive to curious people, liking new experiences.

All in all, we think that the design of our study may have been a fairly good compromise between external and internal validity when measuring action-orientedness, loss aversion and curiosity of entrepreneurs and 'others', where both groups have been defined according to wellmotivated definitions.

Our study links a trait that distinguishes individuals in terms of their tendency to search for novelty within the psychological literature with one that distinguishes individuals in terms of their decision making under uncertainty in the economics literature.

A link can also be made to the (classic) entrepreneurship literature. Participants in our study are all confronted with the same "objective" reality, that is they all observe the same "thing". However, not all opt for taking action. In other words, while all individuals are presented with the same objective facts, not all of them see, discover, explore or exploit this as an opportunity (Shane and Venkataraman, 2000). In fact, curious individuals, by definition, will seek new information and it is this difference that might precisely be what leads some to be alert (Kirzner, 1978) and see and act upon opportunities that might be hidden to others. From this point of 
view, action-orientedness can be related to the concept 'alertness' which has been discussed more widely in the entrepreneurship literature. Further research might address the extent to which alertness to opportunities is indeed related to curiosity.

Provided that personality traits are forged at young ages, policies that foster the development of traits such as curiosity in children will have economic consequences in the long run. Although personality traits are believed to be fairly stable, changes can nevertheless be observed throughout life. Perhaps, people are born as curious children and the current society teaches them to become less curious. In that case the question might rather be how we can maintain these higher levels of curiosity. Further research should lead to indications to what extent and when in life curiosity can best be developed to foster more entrepreneurship.

\section{References}

Baker, T. and Nelson, R. E. (2005). Creating something from nothing: Resource construction through entrepreneurial bricolage. Administrative Science Quarterly, 50(3):329-366.

Bar-Eli, M., Azar, O. H., Ritov, I., Keidar-Levin, Y., and Schein, G. (2007). Action bias among elite soccer goalkeepers: The case of penalty kicks. Journal of Economic Psychology, 28(5):606621.

Baron, J. and Ritov, I. (1994). Reference points and omission bias. Organizational Behavior and Human Decision Processes, 59(3):475-498.

Baron, J. and Ritov, I. (2004). Omission bias, individual differences, and normality. Organizational Behavior and Human Decision Processes, 94(2):74-85.

Baron, R. A. (2000). Counterfactual thinking and venture formation: The potential effects of thinking about "what might have been". Journal of Business Venturing, 15(1):79-91.

Borghans, L., Duckworth, A. L., Heckman, J. J., and Ter Weel, B. (2008). The economics and psychology of personality traits. Journal of Human Resources, 43(4):972-1059.

Burmeister, K. and Schade, C. (2007). Are entrepreneurs' decisions more biased? an experimental investigation of the susceptibility to status quo bias. Journal of Business Venturing, 22(3):340362.

Coe, P. R. and Butterworth, W. (1995). Optimal stopping in "the showcase showdown". The American Statistician, 49(3):271-275.

Dyer, J. H., Gregersen, H. B., and Christensen, C. (2008). Entrepreneur behaviors, opportunity recognition, and the origins of innovative ventures. Strategic Entrepreneurship Journal, $2(4): 317-338$. 
Fehr, E. and Goette, L. (2007). Do workers work more if wages are high? evidence from a randomized field experiment. The American Economic Review, pages 298-317.

Frisch, D. and Baron, J. (1988). Ambiguity and rationality. Journal of Behavioral Decision Making, 1(3):149-157.

Gaechter, S., Johnson, E. J., Herrmann, A., et al. (2010). Individual-level loss aversion in riskless and risky choices. Technical report.

Gneezy, U. and Rustichini, A. (2000). Pay enough or don't pay at all. Quarterly Journal of Economics, pages 791-810.

Golman, R. and Loewenstein, G. (2015). The demand for, and avoidance of, information. Technical report, Mimeo.

Hartog, J., Van Praag, M., and Van Der Sluis, J. (2010). If you are so smart, why aren't you an entrepreneur? returns to cognitive and social ability: Entrepreneurs versus employees. Journal of Economics \& Management Strategy, 19(4):947-989.

Heckman, J. J., Stixrud, J., and Urzua, S. (2006). The effects of cognitive and noncognitive abilities on labor market outcomes and social behavior. Journal of Labor Economics, 24(3):411482.

Holm, H. J., Opper, S., and Nee, V. (2013). Entrepreneurs under uncertainty: An economic experiment in china. Management Science, 59(7):1671-1687.

Holt, C. A. and Laury, S. K. (2002). Risk aversion and incentive effects. The American Economic Review, 92(5):1644-1655.

Kahneman, D., Knetsch, J. L., and Thaler, R. H. (1990). Experimental tests of the endowment effect and the coase theorem. Journal of Political Economy, pages 1325-1348.

Kahneman, D. and Miller, D. T. (1986). Norm theory: Comparing reality to its alternatives. Psychological Review, 93(2):136.

Kahneman, D. and Tversky, A. (1982). The psychology of preferences. Scientific American.

Kashdan, T. B., Gallagher, M. W., Silvia, P. J., Winterstein, B. P., Breen, W. E., Terhar, D., and Steger, M. F. (2009). The curiosity and exploration inventory-ii: Development, factor structure, and psychometrics. Journal of Research in Personality, 43(6):987-998.

Kashdan, T. B., Rose, P., and Fincham, F. D. (2004). Curiosity and exploration: Facilitating positive subjective experiences and personal growth opportunities. Journal of Personality Assessment, 82(3):291-305.

Keynes, J. M. (1936). General theory of employment, interest and money. Palgrave Macmillan. 
Kirzner, I. M. (1978). Competition and Entrepreneurship. University of Chicago press.

Kőszegi, B. (2014). Behavioral contract theory. Journal of Economic Literature, 52(4):1075-1118.

Köszegi, B. and Rabin, M. (2006). A model of reference-dependent preferences. The Quarterly Journal of Economics, pages 1133-1165.

Koudstaal, M., Sloof, R., and Van Praag, M. (2015). Risk, uncertainty and entrepreneurship: Evidence from a lab-in-the-field experiment. Management Science.

Kuhl, J. (1985). Volitional mediators of cognition-behavior consistency: Self-regulatory processes and action versus state orientation. In Action Control, pages 101-128. Springer.

Laureiro-Martínez, D., Canessa, N., Brusoni, S., Zollo, M., Hare, T., Alemanno, F., and Cappa, S. F. (2013). Frontopolar cortex and decision-making efficiency: comparing brain activity of experts with different professional background during an exploration-exploitation task. Frontiers in Human Neuroscience, 7.

Laury, S. (2006). Pay one or pay all: Random selection of one choice for payment. Technical report, Experimental Economics Center, Andrew Young School of Policy Studies, Georgia State University.

Levine, R. and Rubinstein, Y. (2013). Smart and illicit: Who becomes an entrepreneur and does it pay? Technical report, National Bureau of Economic Research.

Loewenstein, G. (1994). The psychology of curiosity: A review and reinterpretation. Psychological Bulletin, 116(1):75.

Markman, G. D., Balkin, D. B., and Baron, R. A. (2002). Inventors and new venture formation: the effects of general self-efficacy and regretful thinking. Entrepreneurship Theory and Practice, $27(2): 149-165$.

McMullen, J. S. and Shepherd, D. A. (2006). Entrepreneurial action and the role of uncertainty in the theory of the entrepreneur. Academy of Management Review, 31(1):132-152.

Patt, A. and Zeckhauser, R. (2000). Action bias and environmental decisions. Journal of Risk and Uncertainty, 21(1):45-72.

Reio, T. G. and Wiswell, A. (2000). Field investigation of the relationship among adult curiosity, workplace learning, and job performance. Human Resource Development Quarterly, 11(1):530.

Reio Jr, T. G. and Callahan, J. L. (2004). Affect, curiosity, and socialization-related learning: A path analysis of antecedents to job performance. Journal of Business and Psychology, 19(1):322. 
Ritov, I. and Baron, J. (1990). Reluctance to vaccinate: Omission bias and ambiguity. Journal of Behavioral Decision Making, 3(4):263-277.

Ritov, I. and Baron, J. (1995). Outcome knowledge, regret, and omission bias. Organizational Behavior and Human Decision Processes, 64(2):119-127.

Samuelson, W. and Zeckhauser, R. (1988). Status quo bias in decision making. Journal of Risk and Uncertainty, 1(1):7-59.

Sandri, S., Schade, C., Mußhoff, O., and Odening, M. (2010). Holding on for too long? an experimental study on inertia in entrepreneurs' and non-entrepreneurs' disinvestment choices. Journal of Economic Behavior \&3 Organization, 76(1):30-44.

Sarasvathy, S. D. (2001). Causation and effectuation: Toward a theoretical shift from economic inevitability to entrepreneurial contingency. Academy of Management Review, 26(2):243-263.

Seibert, S. E., Crant, J. M., and Kraimer, M. L. (1999). Proactive personality and career success. Journal of Applied Psychology, 84(3):416.

Shane, S. and Venkataraman, S. (2000). The promise of entrepreneurship as a field of research. Academy of Management Review, 25(1):217-226.

Shyti, A. and Paraschiv, C. (2014). Risk and ambiguity in evaluating entrepreneurial prospects: An experimental study.

Spranca, M., Minsk, E., and Baron, J. (1991). Omission and commission in judgment and choice. Journal of Experimental Social Psychology, 27(1):76-105.

Tanner, C. and Medin, D. L. (2004). Protected values: No omission bias and no framing effects. Psychonomic Bulletin \& Review, 11(1):185-191.

Tenorio, R. and Cason, T. N. (2002). To spin or not to spin? natural and laboratory experiments from the price is right. The Economic Journal, 112(476):170-195.

Van Dijk, E. and Zeelenberg, M. (2007). When curiosity killed regret: Avoiding or seeking the unknown in decision-making under uncertainty. Journal of Experimental Social Psychology, $43(4): 656-662$.

Van Praag, M., Van Witteloostuijn, A., and Van der Sluis, J. (2013). The higher returns to formal education for entrepreneurs versus employees. Small Business Economics, 40(2):375-396.

Zeelenberg, M., Van den Bos, K., Van Dijk, E., and Pieters, R. (2002). The inaction effect in the psychology of regret. Journal of Personality and Social Psychology, 82(3):314. 
Table 1: Summary of mechanisms underlying action-orientedness, their association with occupational choices and their measurement in our study.

\begin{tabular}{|c|c|c|c|c|c|}
\hline \multirow{2}{*}{ Mechanism } & \multirow{2}{*}{$\begin{array}{l}\text { Effect on } \\
\text { action-orientedness }\end{array}$} & \multicolumn{3}{|c|}{ Occupational choice ${ }^{\ddagger}$} & \multirow{2}{*}{ Measurement } \\
\hline & & Entrepreneurs & Managers & Employees & \\
\hline Loss aversion & - & - & & + & $\begin{array}{l}\text { Multiple price-list } \\
\text { elicitation }\end{array}$ \\
\hline Curiosity & + & + & & - & $\begin{array}{l}\text { Treatment and } \\
\text { questionnaire }\end{array}$ \\
\hline
\end{tabular}

$\nmid \dagger$ The + sign means that the mechanism increases action-orientedness, whereas a - sign means that it decreases action-orientedness.

$\ddagger$ The + sign means that the mechanism is expected to has a positive association with an occupational choice, whereas a - sign means that the expected association is negative.

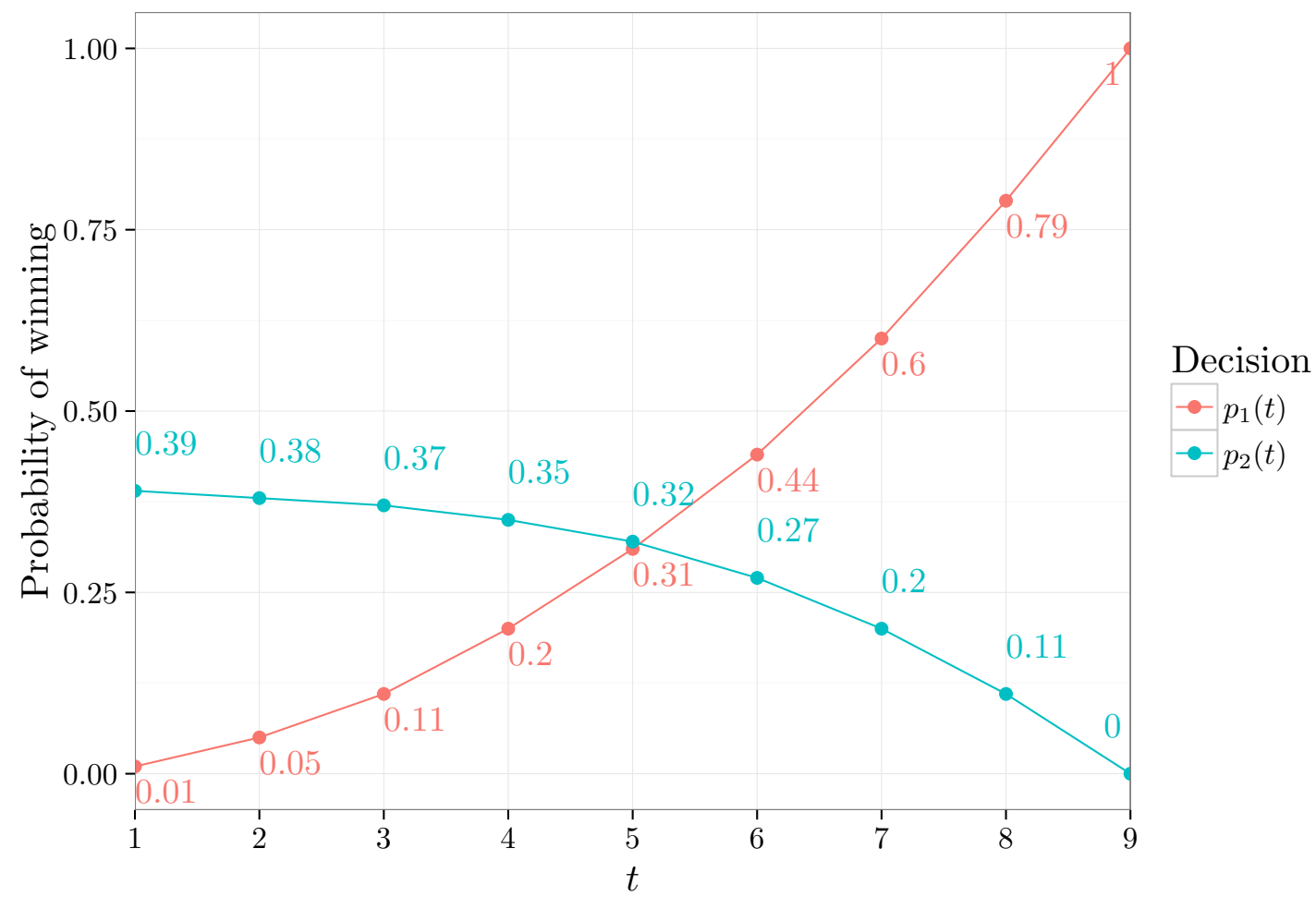

Figure 1: Win probabilities of stop and spin given first spin $t$. 

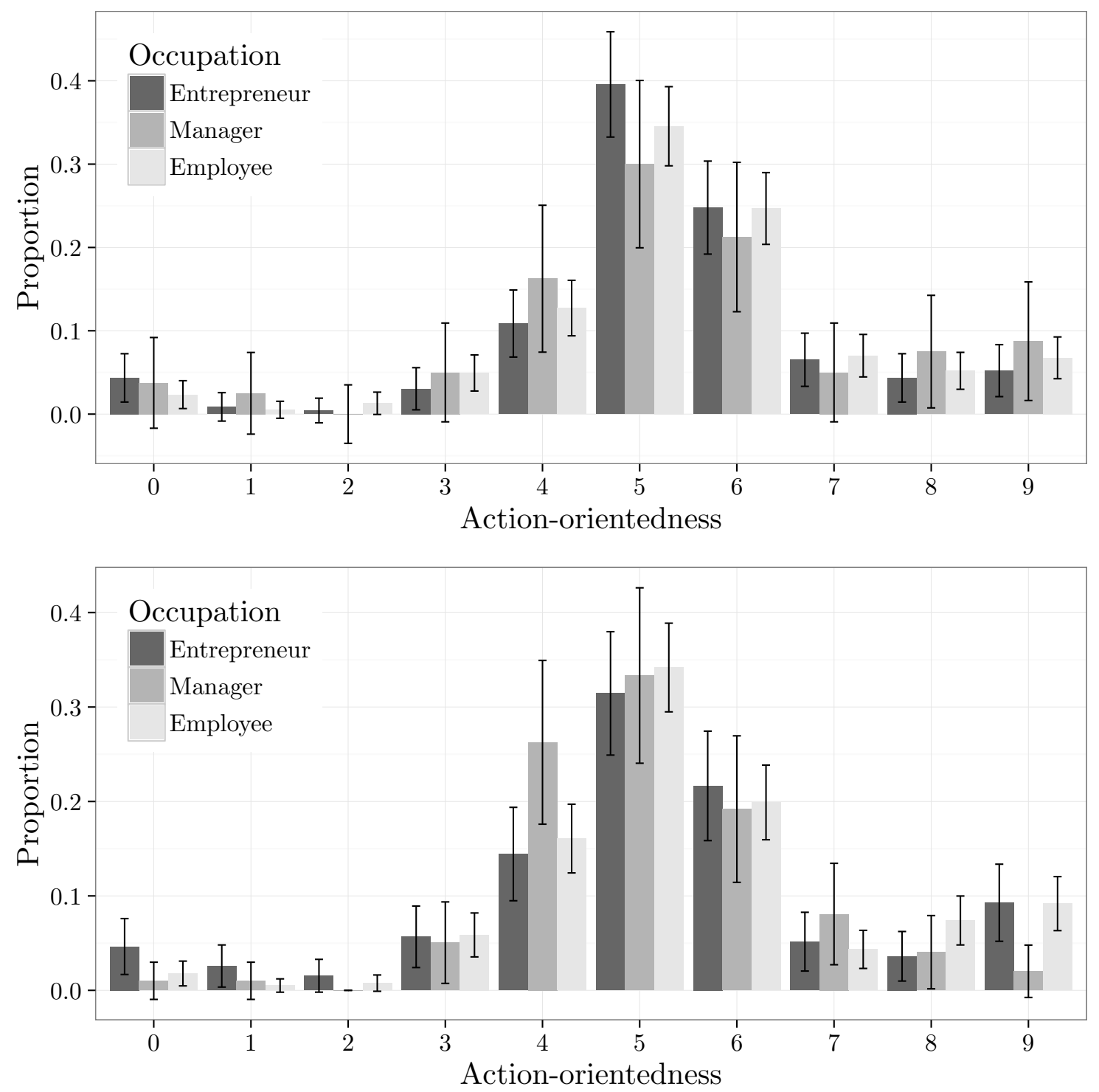

Figure 2: Distribution of action-orientedness across occupations in the baseline (figure above) and counterfactual information (figure below) treatment respectively. Error bars represent 95\% confidence intervals. Standard errors are computed as follow: a categorical variable for each $\omega$ represents the proportion $p$ of participants with strategy $\omega$ and failure is represented by the proportion $1-p$ of participants with strategy $\{0,1,2, \ldots, 9\} \backslash \omega$. The standard error is given by $\sqrt{p(1-p) / n}$ where $n$ represents the number of participants (of a given occupation in a particular treatment). 


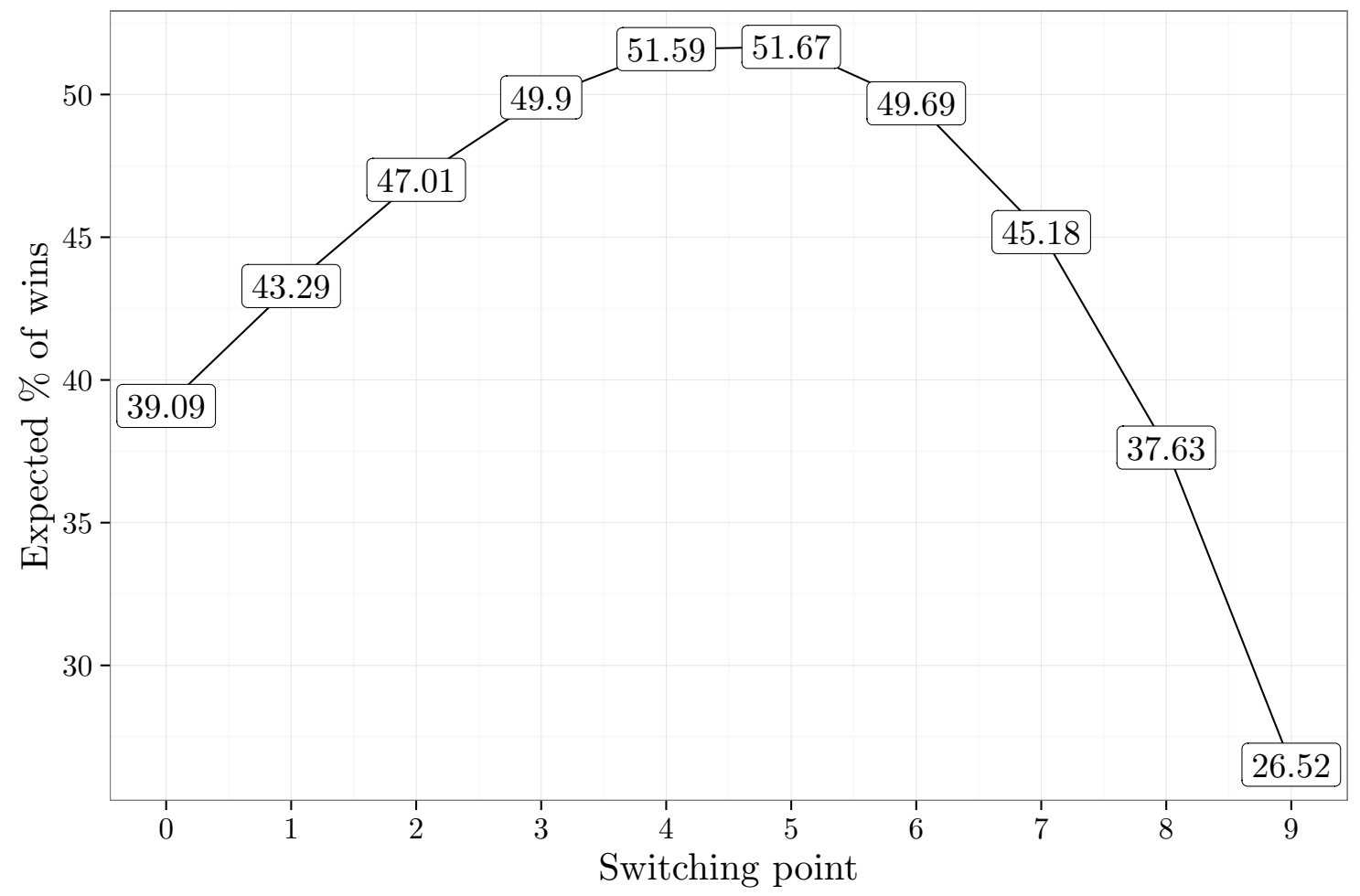

Figure 3: Expected likelihood of winning for a given strategy of play at the wheel. Strategy $\omega \in\{0,1,2, \ldots, 9\}$ means that the participant would spin a second time only if $t \leq \omega$. As an example, $\omega=0$ means that the participant would never spin twice, no matter what the score of the first spin is. As a second example, $\omega=9$ means that the participant would always spin twice, no matter what the score of the first spin is. The optimal strategy is to spin a second time if the score on the first spin is below or equal to 5 , leading to a winning probability of $51.67 \%$. N.B.: A strategy of always spinning (i.e. a switching point of 9) does not always lead to a loss: this strategy will lead to optimal play in all matches where the score on the first spin is below or equal to 5 , and sub-optimal play only in matches where the score on the first spin is greater than 5 . 
Table 2: Descriptive statistics by occupation ${ }^{\dagger}$

\begin{tabular}{|c|c|c|c|c|c|c|}
\hline & \multicolumn{2}{|c|}{$\begin{array}{c}\text { Entrepreneur } \\
\quad(n=322)\end{array}$} & \multicolumn{2}{|c|}{$\begin{array}{l}\text { Manager } \\
(n=141)\end{array}$} & \multicolumn{2}{|c|}{$\begin{array}{l}\text { Employee } \\
(n=594) \\
\end{array}$} \\
\hline Gender (female \%) & 31.68 & $\mathrm{a}$ & 39.01 & $\begin{array}{ll}\mathrm{c} \\
\end{array}$ & 53.03 & $\mathrm{a}, \mathrm{c}$ \\
\hline Age & 50.39 & $\mathrm{a}, \mathrm{b}$ & 45.84 & $\mathrm{~b}, \mathrm{c}$ & 42.67 & $\mathrm{a}, \mathrm{c}$ \\
\hline Education (\%) & & $\mathrm{a}, \mathrm{b}$ & & $\mathrm{b}, \mathrm{c}$ & & $\mathrm{a}, \mathrm{c}$ \\
\hline High school & 4.04 & & 2.84 & & 14.98 & \\
\hline Vocational degree & 11.80 & & 6.38 & & 41.58 & \\
\hline College & 45.34 & & 43.26 & & 29.80 & \\
\hline University & 38.82 & & 47.52 & & 13.64 & \\
\hline Income (\%) & & $\mathrm{a}, \mathrm{b}$ & & $\mathrm{b}, \mathrm{c}$ & & $\mathrm{a}, \mathrm{c}$ \\
\hline Income not provided & 27.33 & & 12.77 & & 13.64 & \\
\hline Less than $€ 25,000$ & 12.73 & & 3.55 & & 34.85 & \\
\hline$€ 25,001-€ 50,000$ & 18.94 & & 17.73 & & 40.74 & \\
\hline$€ 50,001-€ 75,000$ & 12.42 & & 24.11 & & 9.26 & \\
\hline$€ 75,001-€ 125,000$ & 19.25 & & 34.04 & & 1.52 & \\
\hline$€ 125,001-€ 200,000$ & 6.52 & & 6.38 & & 0.00 & \\
\hline$€ 200,001-€ 300,000$ & 0.31 & & 0.71 & & 0.00 & \\
\hline$€ 300,001-€ 400,000$ & 0.93 & & 0.00 & & 0.00 & \\
\hline More than $€ 400,000$ & 1.55 & & 0.71 & & 0.00 & \\
\hline
\end{tabular}

$\dagger$ We have performed z-tests of proportions to compare gender, t-tests to compare age, and Kolmogorov-Smirnov tests to compare income and education.

a Significant difference between entrepreneurs and employees.

b Significant difference between entrepreneurs and managers.

c Significant difference between managers and employees. 
Table 3: Descriptive statistics of action-orientedness, loss aversion, and curiosity per occupation and treatment.

Panel A: Descriptives

\begin{tabular}{|c|c|c|c|c|c|c|c|}
\hline & $\begin{array}{c}\text { Entrepreneur } \\
\quad(n=322)\end{array}$ & $\begin{array}{l}\text { Manager } \\
(n=141)\end{array}$ & \multicolumn{2}{|c|}{$\begin{array}{l}\text { Employee } \\
(n=594)\end{array}$} & \multicolumn{3}{|c|}{$\begin{array}{l}\text { All } \\
(n=1057)\end{array}$} \\
\hline Action-orientedness & 5.03 & 4.85 & 4.96 & & 4.97 & & 0.86 \\
\hline Baseline & 5.10 & 4.93 & 5.03 & $\mathrm{~d}$ & 5.04 & $\mathrm{~d}$ & 0.84 \\
\hline Counterfactual information & 4.94 & 4.80 & 4.90 & $\mathrm{~d}$ & 4.89 & $\mathrm{~d}$ & 0.88 \\
\hline Loss aversion & 3.40 & 3.66 & 3.77 & $\mathrm{a}$ & 3.64 & & 2.37 \\
\hline Curiosity & 36.66 & 35.14 & 30.90 & $\mathrm{a}, \mathrm{c}$ & 33.22 & & 6.85 \\
\hline
\end{tabular}

a Significant difference between entrepreneurs and employees.

b Significant difference between entrepreneurs and managers.

${ }^{\mathrm{c}}$ Significant difference between managers and employees.

d Significant difference between treatments (within the same occupation).

Panel B: Correlations

\begin{tabular}{lcccc}
\hline \hline & & 1 & 2 & 3 \\
\hline Action-orientedness & 1 & - & & \\
Loss aversion & 2 & $-0.12^{* * *}$ & - & \\
Curiosity & 3 & 0.06 & $-0.16^{* * *}$ & - \\
\hline$* \mathrm{p}<0.05^{* *} \mathrm{p}<0.01^{* * *} \mathrm{p}<0.001$ & & &
\end{tabular}

Table 4: Descriptives of sample splits for stricter definitions of entrepreneurs $(n=322)$.

\begin{tabular}{|c|c|}
\hline \multicolumn{2}{|l|}{ Firm age } \\
\hline$\leq 5 \mathrm{yrs}$ & $26 \%$ \\
\hline$>5 \mathrm{yrs}$ & $74 \%$ \\
\hline \multicolumn{2}{|l|}{ Legal structure } \\
\hline Incorporated & $32 \%$ \\
\hline Solde Proprietorship & $55 \%$ \\
\hline Other & $13 \%$ \\
\hline \multicolumn{2}{|c|}{ Number of direct reports } \\
\hline$\leq 10$ & $58 \%$ \\
\hline$>10$ & $42 \%$ \\
\hline
\end{tabular}


Table 5: OLS regressions relating action-orientedness to occupations and behavioral characteristics using subsample where $\omega \in\{3,4,5,6\}$.

\begin{tabular}{|c|c|c|c|c|}
\hline & $(1)$ & $(2)$ & $(3)$ & $(4)$ \\
\hline \multirow[t]{2}{*}{ Counterfactual information } & $-0.1234^{* *}$ & $-0.1141^{* *}$ & $-0.1220^{* *}$ & $-0.1126^{* *}$ \\
\hline & $(0.0531)$ & $(0.0536)$ & $(0.0532)$ & $(0.0535)$ \\
\hline \multirow[t]{2}{*}{ Manager } & $-0.1500^{*}$ & -0.1340 & -0.1333 & -0.1193 \\
\hline & $(0.0902)$ & $(0.0905)$ & $(0.0907)$ & $(0.0908)$ \\
\hline \multirow[t]{2}{*}{ Employee } & $-0.1484^{* *}$ & $-0.1233^{*}$ & -0.1042 & -0.0859 \\
\hline & $(0.0729)$ & $(0.0734)$ & $(0.0758)$ & $(0.0761)$ \\
\hline \multirow[t]{2}{*}{ Loss aversion } & & $-0.0390^{* * * *}$ & & $-0.0354^{* * *}$ \\
\hline & & $(0.0113)$ & & $(0.0115)$ \\
\hline \multirow[t]{2}{*}{ Curiosity } & & & $0.0105^{* *}$ & $0.0081^{*}$ \\
\hline & & & $(0.0044)$ & $(0.0044)$ \\
\hline \multirow[t]{2}{*}{ Constant } & $5.3103^{* * * *}$ & $5.4380^{* * * *}$ & $4.9364^{* * * *}$ & $5.1332^{* * * *}$ \\
\hline & $(0.1832)$ & $(0.1894)$ & $(0.2404)$ & $(0.2524)$ \\
\hline Controls & Yes & Yes & Yes & Yes \\
\hline Observations & 1057 & 1037 & 1051 & 1037 \\
\hline df & 13 & 14 & 14 & 15 \\
\hline p-value & 0.0022 & 0.0001 & 0.0005 & 0.0000 \\
\hline$R^{2}$ & 0.0303 & 0.0420 & 0.0361 & 0.0451 \\
\hline
\end{tabular}

Table 6: OLS regressions relating behavioral characteristics to occupations.

\begin{tabular}{lcc}
\hline & $\begin{array}{c}\text { Loss aversion } \\
(1)\end{array}$ & $\begin{array}{c}\text { Curiosity } \\
(2)\end{array}$ \\
\hline Counterfactual information & 0.0638 & -0.2820 \\
& $(0.1309)$ & $(0.3354)$ \\
Manager & -0.0045 & $-1.5664^{* * *}$ \\
& $(0.2246)$ & $(0.5774)$ \\
Employee & $0.3854^{* *}$ & $-4.8129^{* * * *}$ \\
& $(0.1787)$ & $(0.4576)$ \\
Constant & $3.1875^{* * * *}$ & $36.4506^{* * * *}$ \\
& $(0.4532)$ & $(1.1548)$ \\
Controls & Yes & Yes \\
\hline Observations & 1345 & 1372 \\
df & 13 & 13 \\
p-value & 0.0028 & 0.0000 \\
$R^{2}$ & 0.0233 & 0.2197 \\
\hline \hline
\end{tabular}

Standard errors in parentheses

${ }^{*} p<0.1,{ }^{* *} p<0.05,{ }^{* * *} p<0.01,{ }^{* * * *} p<0.001$

All regressions include controls for background characteristics (age, (age, gender, education and income). 
Table 7: OLS regressions relating action-orientedness to occupations using stricter definitions of entrepreneurs based on company age, income level, legal structure, and number of direct reports using subsample where $\omega \in\{3,4,5,6\}$.

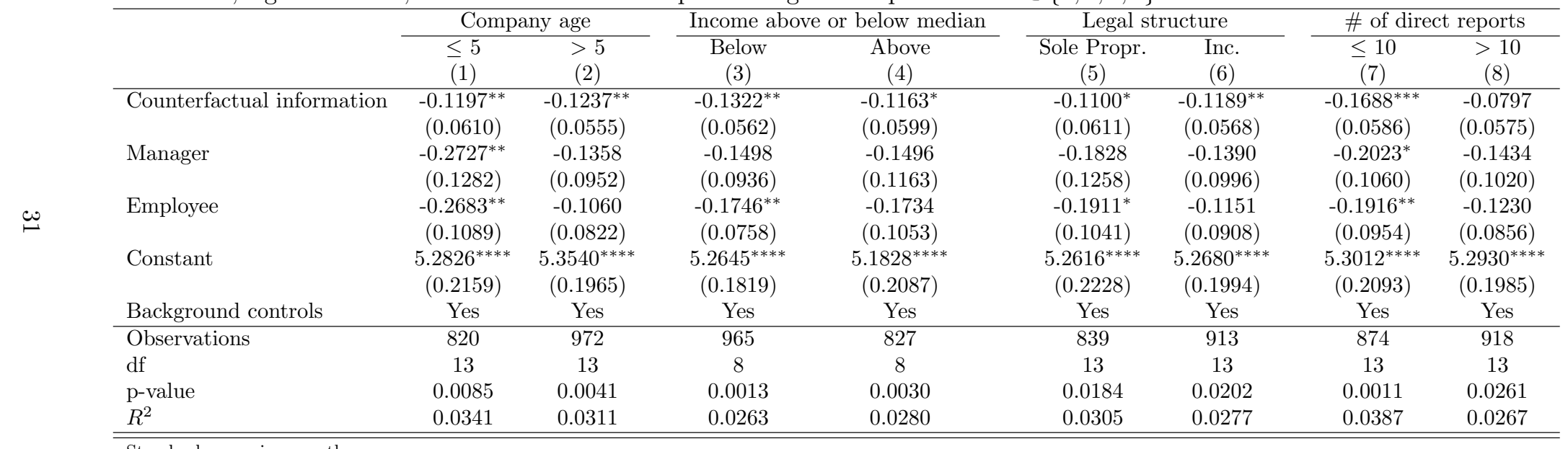

Standard errors in parentheses

$p<0.1,{ }^{* *} p<0.05,{ }^{* * *} p<0.01,{ }^{* * * *} p<0.001$

All regressions include controls for background characteristics (age, gender, education and income) 
Table 8: Treatment effect with interactions using subsample where $\omega \in\{3,4,5,6\}$.

\begin{tabular}{lcccc}
\hline & $(1)$ & $(2)$ & $(3)$ & $(4)$ \\
\hline Counterfactual information & -0.2139 & -0.0787 & -0.7742 & -0.5873 \\
Male & $(0.3664)$ & $(0.3791)$ & $(0.4824)$ & $(0.5064)$ \\
& 0.0367 & 0.0263 & 0.0402 & 0.0259 \\
Male $\times$ Counterfactual information & $(0.0818)$ & $(0.0824)$ & $(0.0819)$ & $(0.0822)$ \\
& $-0.1986^{*}$ & $-0.2270^{*}$ & $-0.2448^{* *}$ & $-0.2651^{* *}$ \\
Manager & $(0.1159)$ & $(0.1170)$ & $(0.1171)$ & $(0.1178)$ \\
& -0.1399 & -0.1342 & -0.1393 & -0.1314 \\
Employee & $(0.1363)$ & $(0.1362)$ & $(0.1365)$ & $(0.1361)$ \\
& -0.1180 & -0.1062 & -0.1089 & -0.0951 \\
Manager $\times$ Counterfactual information & $(0.0998)$ & $(0.1004)$ & $(0.1037)$ & $(0.1039)$ \\
& -0.0349 & -0.0126 & 0.0043 & 0.0188 \\
Employee $\times$ Counterfactual information & $(0.1838)$ & $(0.1841)$ & $(0.1846)$ & $(0.1845)$ \\
& -0.0641 & -0.0339 & 0.0171 & 0.0312 \\
Loss aversion & $(0.1469)$ & $(0.1479)$ & $(0.1529)$ & $(0.1535)$ \\
Counterfactual information $\times$ Loss aversion & & -0.0183 & & -0.0172 \\
& & $(0.0163)$ & & $(0.0165)$ \\
Curiosity & & $-0.0401^{*}$ & & -0.0348 \\
Counterfactual information $\times$ Curiosity & & $(0.0227)$ & & $(0.0230)$ \\
Constant & & & 0.0034 & 0.0025 \\
Background controls & & & $(0.0062)$ & $(0.0063)$ \\
Observations & & & $0.0154^{*}$ & 0.0127 \\
$R^{2}$ & & & $(0.0088)$ & $(0.0090)$ \\
Adjusted- $R^{2}$ & & & & \\
\hline \hline
\end{tabular}

Standard errors in parentheses

${ }^{*} p<0.1,{ }^{* *} p<0.05,{ }^{* * *} p<0.01,{ }^{* * * *} p<0.001$

All regressions include controls for background characteristics (age, gender, education and income). 


\section{A Theory}

\section{A.1 Optimal strategy in the optimal stopping game}

In this appendix we derive the expressions for $p_{1}(t)$ and $p_{2}(t)$ stated in Subsection 3.1, based on Coe and Butterworth (1995).

Let the outcome of the first spin equal $t$ and suppose player 1 takes a second spin. With probability $\frac{1}{N}$ the second spin results in a 1 and thus a total score of $t+1$. With this overall score, player 1 has a probability $p_{1}(t+1)$ of winning (note that for player 1 to win, it does not matter whether total score $t+1$ was reached in just one spin or in two spins). Continuing this type of reasoning, with probability $\frac{1}{N}$ the second spin results in a 2 and the probability to win equals $p_{1}(t+2)$, and so on. If the second spin exceeds $N-t$ player 1 goes over the upper limit and loses for sure. Hence the overall probability to win by taking a second spin, conditional on the first spin being equal to $t$, equals $p_{2}(t)=\frac{1}{N} \cdot \sum_{s=1}^{N-t} p_{1}(t+s)$.

Next suppose player 1 stops after her first spin, such that her total score equals $T 1=t$. Let $c_{1}$ denote the outcome of player 2's first spin and $T 2$ its overall score. Assuming that player 2 follows its optimal strategy, it then holds that:

$$
\begin{aligned}
p_{1}(t)= & \operatorname{Pr}\left(c_{1}<t \text { and } T 2=t \mid T 1=t\right)+\operatorname{Pr}(T 2<t \mid T 1=t) \\
& +\sum_{i=1}^{t} \operatorname{Pr}\left(c_{1}=i \text { and } T 2>N \mid T 1=t\right) \\
= & \frac{(t-1)}{N} \cdot \frac{1}{N}+\frac{\left(\begin{array}{c}
t-1 \\
2
\end{array}\right)}{N \cdot N}+\sum_{i=1}^{t} \frac{1}{N} \cdot \frac{i}{N}=\frac{t^{2}}{N^{2}}
\end{aligned}
$$

Here $\operatorname{Pr}(T 2<t \mid T 1=t)=\left(\begin{array}{c}t-1 \\ 2\end{array}\right) / N^{2}$ follows from Coe and Butterworth (1995), or from observing that $\operatorname{Pr}(T 2<t \mid T 1=t)=\sum_{i=1}^{t-2} \frac{1}{N} \cdot \frac{(t-1-i)}{N}=\frac{1}{N^{2}}\left(\frac{(t-1)(t-2)}{2}\right)=\left(\begin{array}{c}t-1 \\ 2\end{array}\right) / N^{2}$. Using the standard formulas for the sums $\sum_{i=1}^{t} i=\frac{1}{2} t(t+1)$ and $\sum_{i=1}^{t} i^{2}=\frac{t(t+1)(2 t+1)}{6}$, the overall expressions follow. ${ }^{12}$

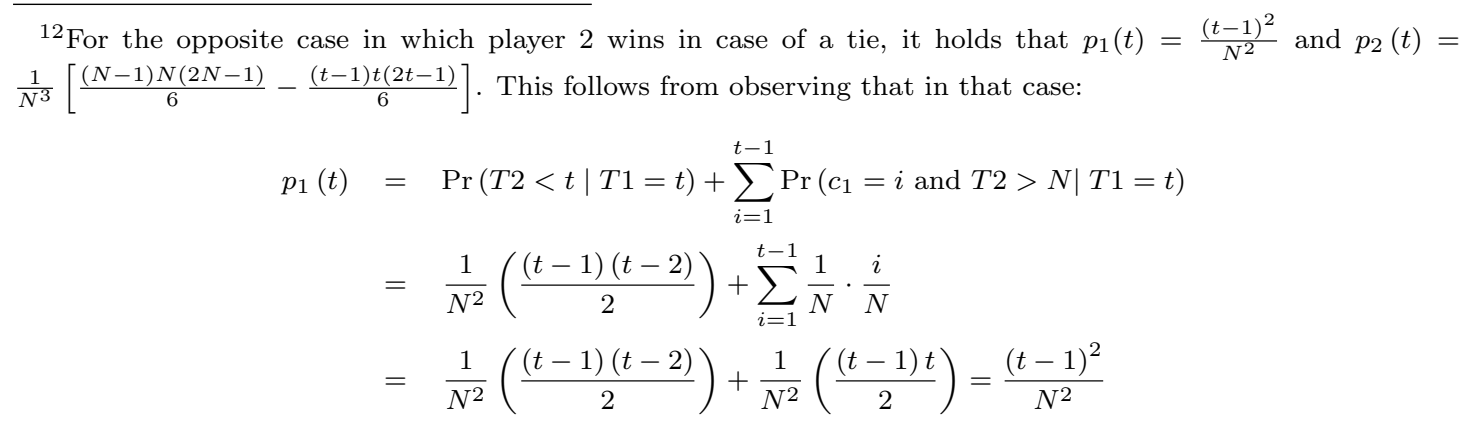
From $p_{2}(t)=\frac{1}{N} \cdot \sum_{s=1}^{N-t} p_{1}(t+s)$ and using the standard formula for $\sum i^{2}$ the expression for $p_{2}(t)$ follows. 


\section{A.2 Loss aversion}

In this appendix we formally derive the effect of loss aversion on the spin decision, i.e. inequalities (2) and (3).

First suppose the reference action equals $R=$ Stop after both choices. As in the main text, let $p_{1}^{2 \text { Loss }}(t) \equiv E\left(p_{1}(t) \mid\right.$ spinning twice led to a Loss) be the (ex ante) conditional expectation of the probability that, given that spinning twice led to a loss for player 1 , spinning only once would have given her a win. Similarly so, let $p_{1}^{2 W i n}(t) \equiv E\left(p_{1}(t) \mid\right.$ spinning twice led to a Win). With reference dependent preferences as in Subsection 3.2, the expected utility of spinning twice then equals:

$$
E\left[U_{2}^{R=S t o p}(t)\right]=p_{2}(t) \cdot X+p_{2}(t) \cdot\left(1-p_{1}^{2 W i n}(t)\right) \cdot \eta X-\left(1-p_{2}(t)\right) \cdot p_{1}^{2 \text { Loss }}(t) \cdot \lambda \eta X
$$

This can be rewritten as:

$$
\begin{gathered}
E\left[U_{2}^{R=S t o p}(t)\right]=p_{2}(t) \cdot\left(1+\eta+(\lambda-1) \eta \cdot p_{1}^{2 \text { Loss }}(t)\right) \cdot X \\
-\eta\left[\left(1-p_{2}(t)\right) \cdot p_{1}^{2 \text { Loss }}(t)+p_{2}(t) \cdot p_{1}^{2 \text { Win }}(t)\right] \cdot X-(\lambda-1) \eta \cdot p_{1}^{2 \text { Loss }}(t) \cdot X
\end{gathered}
$$

Making use of the fact that, by definition $p_{1}(t) \equiv\left(1-p_{2}(t)\right) \cdot p_{1}^{2 \operatorname{Los} s}(t)+p_{2}(t) \cdot p_{1}^{2 W i n}(t)$, this reduces to:

$$
\begin{gathered}
E\left[U_{2}^{R=S t o p}(t)\right]=p_{2}(t) \cdot\left(1+\eta+(\lambda-1) \eta \cdot p_{1}^{2 \text { Loss }}(t)\right) \cdot X \\
-\eta \cdot p_{1}(t) \cdot X-(\lambda-1) \eta \cdot p_{1}^{2 \text { Loss }}(t) \cdot X
\end{gathered}
$$

Given that if player 1 stops the reference point equals the action actually chosen, we immediately obtain for the expected utility of stopping:

$$
E\left[U_{1}^{R=S t o p}(t)\right]=p_{1}(t) \cdot X
$$

Inequality (2) now follows from comparing the two expected payoffs (5) and (6) and rewriting.

To fully characterize inequality $(2)$, we observe that $p_{1}^{2 L o s s}(t)=p_{1}(t) \cdot \frac{t}{N}$. This holds because the only instances where taking a second spin led to a loss while spinning once would have given a win, are the ones where the second spin makes that player 1 goes over $N$. For a first spin equal to $t$ this happens with probability $\frac{t}{N}$. And winning with a total score of $t$ happens with probability $p_{1}(t)$.

Next suppose the reference action equals $R=S$ pin after both choices. Define $p_{2}^{1 \text { Loss }}(t) \equiv$ $E\left(p_{2}(t) \mid\right.$ stopping led to a Loss $)$ and, similarly, $p_{2}^{1 \text { Win }}(t) \equiv E\left(p_{2}(t) \mid\right.$ stopping led to a Win). Given that if player 1 takes a second spin the reference point equals the action actually chosen, 
expected utility of spinning twice simply equals:

$$
E\left[U_{2}^{R=S p i n}(t)\right]=p_{2}(t) \cdot X
$$

From a symmetric reasoning as for $E\left[U_{2}^{R=S t o p}(t)\right]$ in (5), we immediately obtain: ${ }^{13}$

$$
\begin{gathered}
E\left[U_{1}^{R=S p i n}(t)\right]=p_{1}(t) \cdot\left(1+\eta+(\lambda-1) \eta \cdot p_{2}^{1 \text { Loss }}(t)\right) \cdot X \\
-\eta \cdot p_{2}(t) \cdot X-(\lambda-1) \eta \cdot p_{2}^{1 \text { Loss }}(t) \cdot X
\end{gathered}
$$

Inequality (3) then follows from comparing the two expected payoffs (7) and (8) and rewriting.

Also here we can fully characterize inequality (3) by providing a closed form solution for $p_{2}^{1 \text { Loss }}(t)$. This can be most easily done by noting that by definition $p_{2}^{L^{L o s s}}(t)=\frac{p_{2}(t)-p_{1}(t) \cdot p_{2}^{1 W^{i n}}(t)}{\left(1-p_{1}(t)\right)}$, and arguing that $p_{2}^{1 \text { Win }}(t)=\left(1-\frac{t}{N}\right)$. The latter follows because, given the observed win after having spun only once, for the very same computer draw(s) player 1 would have won after spinning twice as well if this would keep her in the race (i.e. $t+s \leq N$ ). Now for a given first spin $t$, there are $N-t$ values for $s$ out of the overall $N$ that keep her in the race, each of them equally likely. This gives $p_{2}^{1 W i n}(t)=\frac{N-t}{N}=\left(1-\frac{t}{N}\right)$. Overall, $p_{2}^{1 \text { Loss }}(t)=\frac{p_{2}(t)-p_{1}(t) \cdot\left(1-\frac{t}{N}\right)}{\left(1-p_{1}(t)\right)}$.

We finally discuss the case where the reference action equals the 'the road not taken'. That is, $R=$ Stop in case one chooses to spin and $R=$ Spin if one chooses to stop. In that case the relevant expected utilities are given by (5) and (8) respectively. Intuitively, loss aversion is then felt after both choices and the relevant question becomes after which choice it is felt more often. This tradeoff depends on the sign of $\left(p_{1}^{2 \text { Loss }}(t)-p_{2}^{1 \text { Loss }}(t)\right)$. If this term is positive, loss aversion is felt more often after spinning twice, which makes stopping relatively more attractive. But if the term is negative, loss aversion is felt more strongly after stopping and spinning twice becomes relatively more attractive. Indeed, comparing (5) and (8) yields that player 1 is predicted to take a second spin iff:

$$
p_{2}(t) \geq p_{1}(t)+\frac{\left(1-p_{1}(t)\right) \cdot(\lambda-1) \eta \cdot\left(p_{1}^{2 \text { Loss }}(t)-p_{2}^{1 \text { Loss }}(t)\right)}{1+2 \eta+(\lambda-1) \eta \cdot p_{1}^{2 \text { Loss }}(t)}
$$

Te r.h.s. of (9) is negative and weakly decreasing in $\lambda$ whenever $p_{1}^{2 \text { Loss }}(t)<p_{2}^{1 \text { Loss }}(t)$. It appears that this necessarily holds at the switching point defined by (9). ${ }^{14}$ Comparative statics

\footnotetext{
${ }^{13}$ Note that after stopping, player 1 has almost complete knowledge about what would have happened had she taken the second spin. That is, she learns $t$ and $s$ and the computer's winning score (after having spun either once or twice). Only if $t<c_{1}$ player 1 does not observe the would be second spin $c_{2}$ of the computer. As for $E\left[U_{2}^{R=S t o p}(t)\right]$ in (5), we assume that in these instances player 1 takes ex ante expectations over $c_{2}$.

${ }^{14}$ To see this, first note that:

$$
\frac{\partial}{\partial \lambda}(\text { r.h.s. of }(9))=\frac{(1+2 \eta) \eta \cdot\left(1-p_{1}(t)\right) \cdot\left(p_{1}^{2 \text { Loss }}(t)-p_{2}^{1 \text { Loss }}(t)\right)}{\left(1+2 \eta+(\lambda-1) \eta \cdot p_{1}^{L \text { Loss }}(t)\right)^{2}}
$$

The r.h.s. of (9) is thus (weakly) decreasing in $\lambda$ whenever $p_{1}^{2 \text { Loss }}(t)<p_{2}^{1 \text { Loss }}(t)$. Now, $p_{1}^{2 \text { Loss }}(t)=\frac{t}{N}$. $p_{1}(t)<\frac{p_{2}(t)-p_{1}(t) \cdot\left(1-\frac{t}{N}\right)}{\left(1-p_{1}(t)\right)}=p_{2}^{1 \text { Loss }}(t)$ whenever $\frac{t}{N} \cdot p_{1}(t) \cdot\left(1-p_{1}(t)\right)<p_{2}(t)-p_{1}(t) \cdot\left(1-\frac{t}{N}\right)$, i.e. whenever
} 
are thus exactly the same as with (3).

In short, the general driving force behind the above predictions is that, when moving from the baseline to the counterfactual information treatment, loss aversion is not only felt after spinning twice, but also (or perhaps exclusively) after stopping. This makes spinning twice relatively more attractive in the counterfactual information treatment and reverses the comparative statics in $\lambda$ as compared to the baseline treatment.

\section{A.3 Curiosity}

In this appendix we discuss an extension of the theory in Subsection 3.3, along the lines of Golman and Loewenstein (2015). They build on Loewenstein's (1994) information gap perspective where curiosity arises from a discrepancy between one's actual knowledge and one's informational reference point, i.e. what one wants to know. Although Loewenstein (1994) draws a parallel with other reference point theories including prospect theory, Golman and Loewenstein (2015)'s formalization cannot be captured by the reference dependent preferences model in Subsection 3.2 simply by choosing $r$ appropriately. However, the ensuing analysis has in common with the one in Subsection 3.2 that moving from the baseline treatment to the counterfactual information treatment, induces a shift in the (now informational) reference point. The broader perspective is thus the same: both loss aversion and curiosity arise from comparison with a reference point, with the reference point shifting when information about the second would be spin is always provided.

In our extension we assume that there are two potentially activated questions player 1 might be curious about. First, like in the main text player 1 may be curious about the outcome of his (would be) second spin $s$ (labelled question $Q_{s}$ ). Second, player 1 may also be curious about the outcome of the game, i.e. who wins (question $Q_{X}$ ). The first question receives attention weight $w_{s}$, the second weight $w_{X}$. Golman and Loewenstein (2015) assume that these attention weights are strictly increasing in the question's importance $\gamma_{i}$, its salience $\sigma_{i}$ and the surprise $\delta_{i}$ associated with it. Salience is taken to be exogenous; it reflects the degree to which a particular context highlights the question. Moreover, Golman and Loewenstein envisage salience as a necessary condition for a question to be activated, i.e. for $w_{i}>0$, while importance is not. In line with this, we assume that in the baseline treatment curiosity is mainly about the second spin, i.e. $w_{s}>w_{X}=0$. Put differently, $Q_{s}$ is salient while $Q_{X}$ is not. As discussed in the main text, in that case the optimal strategy is characterized by (4). ${ }^{15}$ In contrast, in the counterfactual information treatment where player 1 always gets to know the second spin, curiosity shifts towards

$p_{2}(t)>p_{1}(t)-\frac{t}{N} \cdot\left(p_{1}(t)\right)^{2}$. So when $p_{1}(t)-\left(\frac{t}{N}\right)^{3}<p_{2}(t)<p_{1}(t)$, condition (9) will be satisfied (only) if $\lambda$ is high enough. For $p_{2}(t) \geq p_{1}(t)$ condition (9) is always strictly satisfied independent of $\lambda$. Similarly so, for $p_{2}(t) \leq p_{1}(t)-\left(\frac{t}{N}\right)^{3}$ condition (9) is never satisfied irrespective of $\lambda$. Therefore (9) can only hold with equality if $\left(p_{1}^{2 \text { Loss }}(t)-p_{2}^{1 \text { Loss }}(t)\right)<0$.

${ }^{15}$ It might be argued that the relevant question that is activated in the baseline treatment is 'Does the outcome of the second spin increase my winning chances?', rather than 'What is the outcome of the second spin?'. In particular, if the first spin equals $t=N$, why would one be interested in the second spin per se? If $Q_{s}$ takes this alternative form of improved winning chances (either yes or no), the corresponding inequality for the baseline 
the outcome of the game $\left(w_{X}>0\right) \cdot{ }^{16}$

Curiosity about the outcome of the game is again measured with the same inverse measure of entropy. Let $p$ denote the probability of a win. Clarity is then measured by $H(p) \equiv p \ln (p)+$ $(1-p) \ln (1-p)$. Note that $H(p) \leq 0$ necessarily. With the convention that $0 \ln 0=0$ it follows that $H(0)=H(1)=0$. Moreover, $\frac{\partial H}{\partial p}=\ln \left(\frac{p}{1-p}\right)$ and $\frac{\partial^{2} H}{\partial p^{2}}=\frac{1}{p}+\frac{1}{1-p}>0$. Hence $H(p)$ is strictly convex, decreasing for $p<\frac{1}{2}$ and increasing for $p>\frac{1}{2}$. Intuitively, clarity is smallest for $p=\frac{1}{2}$, i.e. when either answer to the win or lose question is equally likely.

With $w_{X}>0$ the preference intensity for clarity about the outcome of the game (question $Q_{X}$ ), the expected utilities of the two choices become:

$$
\begin{gathered}
E\left[U_{1}^{Q_{X}}(t)\right]=p_{1}(t) \cdot X+w_{X} \cdot H\left(p_{1}(t)\right) \\
E\left[U_{2}^{Q_{X}}(t)\right]=p_{2}(t) \cdot X+w_{X} \cdot \sum_{s=1}^{N-t} \frac{1}{N} \cdot H\left(p_{1}(t+s)\right) \\
=\sum_{s=1}^{N-t} \frac{1}{N} \cdot\left\{p_{1}(t+s) \cdot X+w_{X} \cdot H\left(p_{1}(t+s)\right)\right\}
\end{gathered}
$$

Intuitively, spinning twice may increase clarity about $Q_{X}$, because after taking a second spin it may be more clear what the likely outcome will be. For instance, suppose player's 1 first spin equals $t=N-1$. If player 1 stops the outcome is not entirely clear yet, because player 1 loses if the computer's overall score would equal $N$ but wins othewise. Thus, $H\left(p_{1}(t)\right)=H\left(\left(\frac{N-1}{N}\right)^{2}\right)<0$. In contrast, taking a second spin makes that one will know the outcome for sure in advance, i.e. already before the computer takes its turn. If the second spin equals $s=1$ player 1 wins for sure, otherwise he certainly loses. ${ }^{17}$ Obviously, in this case increasing clarity by taking a second spin comes at the cost of subtantially reducing winning chances.

Yet spinning twice not necessarily always improves clarity. For $t=1$ the outcome after stopping is quite clear; player 1 is then almost certain to lose (viz. with probability $\frac{N^{2}-1}{N^{2}}$ ).

treatment becomes:

$$
\begin{aligned}
p_{2}(t) \cdot X+w_{s} \cdot 0 & \geq p_{1}(t) \cdot X+w_{s} \cdot H\left(\frac{t}{N}\right) \\
& \Longleftrightarrow p_{1}(t)+w_{s} \cdot \frac{H\left(\frac{t}{N}\right)}{X}
\end{aligned}
$$

where $H(p) \equiv p \ln (p)+(1-p) \ln (1-p) \leq 0$ as discussed below. Comparing the above inequality with (4), the same qualitative implications are obtained. That is, taking a second spin becomes relatively more atttractive in the presence of curiosity motives and, for a given first spin $t$, this becomes more so the larger $w_{s}$ is.

${ }^{16}$ Note that in the experiment we make use of the strategy method to elicit each subject's switching point. When filling in the questionnaire subjects do not learn the computer's overall score; only actual prize winners get to know this a couple of weeks later. Therefore, this curiosity is not immediately resolved by knowing that one will immediately learn whether one has won the game or not.

${ }^{17}$ In algebraic terms: $\frac{1}{N} \cdot\left\{p_{1}(N) \ln \left(p_{1}(N)\right)+\left(1-p_{1}(N)\right) \ln \left(1-p_{1}(N)\right)\right\}=\frac{1}{N} \cdot\{1 \cdot \ln (1)+(0) \cdot \ln (0)\}=0$, so maximum clarity. 
Spinning twice improves winning chances, but makes it a priori less clear what the outcome will be. If weight $w_{X}$ becomes very high, player 1 effectively only cares about clarity and would stop for very low values of $t$ (yielding an almost sure loss) and spin another time for high values of $t$ (again an almost sure loss), just to increase clarity. This does not occur as particularly plausible behavior. We thus assume that $w_{X}$ is sufficiently small such that player 1 employs a 'regular' cutoff strategy, in which she spins for low values of $t$ and does not spin for high values of $t$. From (10) and (11) above it follows that a sufficient condition for this is that $p_{1}(t) \cdot X+w_{X} \cdot H\left(p_{1}(t)\right)$ is strictly increasing in $t$. For $p_{1}(t)=\frac{t^{2}}{N^{2}}$ this holds whenever:

$$
w_{X}<\frac{1}{\ln \left(N^{2}-1\right)} \cdot X
$$

In that case $E\left[U_{1}^{Q_{X}}(t)\right]$ is certainly increasing in $t$ and $E\left[U_{2}^{Q_{X}}(t)\right]$ certainly decreasing.

The question of main interest is how curiosity about $Q_{X}$ affects spinning choices if the above condition on $w_{X}$ is satisfied. Intuitively, taking a second spin then typically increases expected clarity, because player 1 either increases winning chances, which reduces unclarity if the increase is substantial enough, or player 1 goes over $N$ and is certain to lose. So in general, curiosity about $Q_{X}$ makes spinning a second time also more attractive. Comparing (10) and (11), the governing inequality for the counterfactual information treatment becomes:

$$
p_{2}(t) \geq p_{1}(t)-w_{X} \cdot \frac{\left[\sum_{s=1}^{N-t} \frac{1}{N} \cdot H\left(p_{1}(t+s)\right)-H\left(p_{1}(t)\right)\right]}{X}
$$

The term within square brackets [.] reflects the difference in expected clarity between the two choice options. It is positive when the outcome after spinning twice is more clear on average than the expected clarity after stopping. The term is negative when spinning twice leads to less clarity in expectation than stopping does.

Comparing (12) with (4) in the main text, it holds for all $N>2$ that: ${ }^{18}$

$$
\left[\sum_{s=1}^{N-t} \frac{1}{N} \cdot H\left(p_{1}(t+s)\right)-H\left(p_{1}(t)\right)\right]<\ln (N)
$$

The difference in expected clarity between the two choices in the counterfactual information treatment regarding question $Q_{X}$ is smaller than the difference in expected clarity between the two choices in the baseline treatment regarding question $Q_{s}$. Therefore, for similar sized weights $w_{s}$ and $w_{X}$, the r.h.s. in (12) is necessarily larger than the r.h.s. in (4). In that case, player 1 is more likely to spin a second time in the baseline treatment than in the counterfactual information treatment. Moreover, the r.h.s. in (12) is decreasing in weight $w_{X}$ iff the term within square brackets [.] is positive. This appears to hold for the cutoff that makes player 1 indifferent between

\footnotetext{
${ }^{18}$ This follows from observing that the first term on the l.h.s. is necessarily non-positive while the function $H(p)$ arrives its global minimum of $\ln \left(\frac{1}{2}\right)$ on $p \in[0,1]$ for $p=\frac{1}{2}$. Now $-H(p) \leq-\ln \left(\frac{1}{2}\right)=\ln (2)<\ln (N)$ iff $N>2$.
} 
stopping and spinning twice, i.e. the value of $t$ for which (12) becomes an equality. Therefore, an increase in $w_{X}$ makes player 1 more likely to spin a second time in the counterfactual information treatment. ${ }^{19}$

\section{B Instructions}

A Dutch preview of the survey can be found at the following address: https://qeurope.eu. qualtrics. com/SE/?SID=SV_5jPPykvQK5Utw1L.

\section{B.1 The Showcase Showdown}

The following instructions are provided to the participants during the Showcase Showdown sessions:

In this section we ask you to make decisions in a game similar to the 'Showcase Showdown'. In this game, the computer assumes the role of your opponent. You start as the first player.

You will soon see on your screen a wheel divided into nine equal parts. Each part contains a (different) number between 1 and 9. In the game, you - figuratively! - spin the wheel one or two times. Each spin results in a number between 1 and 9 (all with equal probability). If you spin once your total score is equal to the result of the wheel. If you spin two times, your total score equals the sum of those two outcomes. After you have determined your total score, it is your opponent's turn, which will also spin the wheel once or twice. The person who comes closest to a total score of 9, without going over it, wins. (Stated simply, with a total score above nine you are 'dead'.) You win if both players have the same score.

Your opponent plays his / her role optimally: if your total score is greater than nine, the opponent spins only once and always wins. If your total score is 9 or lower, then your opponent will spin a second time if the first spin does not make him / her win.

${ }^{19}$ To see this, from $H(p)$ strictly convex it follows from Jensen's inequality that:

$$
\sum_{s=1}^{N-t} \frac{1}{N} \cdot H\left(p_{1}(t+s)\right)>H\left(\sum_{s=1}^{N-t} \frac{1}{N} \cdot p_{1}(t+s)\right)=H\left(p_{2}(t)\right)
$$

Let $\Delta\left(t ; w_{X}\right) \equiv E\left[U_{2}^{Q_{X}}(t)\right]-E\left[U_{1}^{Q_{X}}(t)\right]$ denote the difference in expected payoffs between spinning twice and stopping. The assumption made that $w_{X}<\frac{1}{\ln \left(N^{2}-1\right)} \cdot X$, implies that $\Delta\left(t ; w_{X}\right)$ is decreasing in $t$. Let $t^{*}$ be the cutoff value in the absence of curiosity motivations, i.e. the value of $t$ that solves $\Delta(t ; 0)=0$ and thus $p_{2}\left(t^{*}\right)=p_{1}\left(t^{*}\right)$. Simliarly so, let $t^{* *}$ be the cutoff value in the presence of curiosity motivations, i.e. the solution to $\Delta\left(t ; w_{X}\right)=0$. Evaluating $\Delta\left(t ; w_{X}\right)$ at $t=t^{*}$ we obtain using (13) above that $\Delta\left(t^{*} ; w_{X}\right)=$ $w_{X} \cdot\left[\sum_{s=1}^{N-t} \frac{1}{N} \cdot H\left(p_{1}\left(t^{*}+s\right)\right)-H\left(p_{1}\left(t^{*}\right)\right)\right]>w_{X} \cdot\left[H\left(p_{2}\left(t^{*}\right)\right)-H\left(p_{1}\left(t^{*}\right)\right)\right]=0$. Hence necessarily $t^{* *}>t^{*}$. With $\Delta\left(t ; w_{X}\right)$ decreasing in $t$ for all $w_{X}$, thus also necessarily $\Delta\left(t^{* *} ; 0\right)<0$, i.e. $p_{2}\left(t^{* *}\right)<p_{1}\left(t^{* *}\right)$. As a result, at cutoff $t^{* *}$ that equalizes (12), the term within square brackets is necessarily positive. Finally, using implicit differentiation of $\Delta\left(t^{* *} ; w_{X}\right)=0$ we get:

$$
\operatorname{sign}\left(\frac{\partial t^{* *}}{\partial w_{x}}\right)=\operatorname{sign}\left[\sum_{s=1}^{N-t} \frac{1}{N} \cdot H\left(p_{1}\left(t^{* *}+s\right)\right)-H\left(p_{1}\left(t^{* *}\right)\right)\right]>0
$$


[As a slight variation on the above game, we will always let you see the outcome of your 2nd pendulum, so even if you decide just to hurl once. In that case, of course, what counts is the outcome of your first pendulum, but you 'll get so also hear what your total score would have been had you chosen for swinging twice.]

We will first play two practice rounds to gain experience.

The paragraph in brackets only appears for participants that are randomly assigned to the treatment group. The following instructions are provided after the participants have completed the two practice rounds:

After these two practice rounds, we would like to know your real decisions in this game. We therefore ask you for your switching point. That is, for the results of the first spin, would you spin a second time or not?

After you have determined your tipping point, your strategy will be applied in a final round against the computer, if you are among the 20 winners. If you win this round, you will receive $€ 100$ (if you are among the 20 winners). If you lose this round, you will receive $€ 0$. As in the practice rounds you get (if you are among the 20 winners) to know the results of you and your opponent's spins. [Also, you are always informed about your second spin, even if it does not count.] These outcomes are determined by the notary independently.

The sentence in brackets only appears for participants that are randomly assigned to the treatment group.

\section{B.2 Curiosity}

The following questions are presented to participants with a five-point Likert-like scale ranging from 1 ("Very Slightly or Not At All (1)") to 5 ("Extremely"):

Rate the statements below for how accurately they reflect the way you generally feel and behave. Do not rate what you think you should do, or wish you do, or things you no longer do. Please be as honest as possible.

- I actively seek as much information as I can in new situations.

- I am the type of person who really enjoys the uncertainty of everyday life.

- I am at my best when doing something that is complex or challenging.

- Everywhere I go, I am out looking for new things or experiences.

- I view challenging situations as an opportunity to grow and learn.

- I like to do things that are a little frightening.

- I am always looking for experiences that challenge how I think about myself and the world.

- I prefer jobs that are excitingly unpredictable. 
- I frequently seek out opportunities to challenge myself and grow as a person.

- I am the kind of person who embraces unfamiliar people, events, and places.

\section{B.3 Loss Aversion}

The following instructions are provided to the participants at the loss aversion elicitation phase of the experiment:

In this section we always ask you to choose between two options:

Option A: $50 \%$ chance to win $€ 300$ and a $50 \%$ chance to lose $€$ ?, wherein ? varies from 0 to 350 (in steps of 50)

Option B: $€ 0$ with certainty

If the potential loss is low (say $€$ ? Is equal to $€ 0$ ) then most people choose Option A, while a high potential loss (say $€$ ? is equal to $€ 350$ ), most people will prefer Option B. We are interested in the potential loss $€$ ? where you 'switch' from Option A to Option B. In order to determine this switching point as efficient and simple as possible, we present to you three or four decisions that automatically lead to your switching point.

If you are selected as one of the 20 winners, the notary will first randomly determine the potential loss amount that applies to you, then watch (based on your tipping point), or please choose option A or option B. If this option A, the notary tosses a coin to determine whether you win $€ 300$, or you will lose the previously drawn randomly loss amount.

The amount you win or lose at this stage will be added to or deducted from your earnings in the previous stages.

\section{Robustness of Results to the Inclusion of Outliers}

To show that the results shown above are not due to the exclusion of extreme action-orientedness ( $\omega \in\{0,1,2,7,8,9\}$ ), we run a regression of the switching point on gender, age, education, income and occupation using a multinomial logit model with the entire sample ${ }^{20}$. The multinomial logit estimates the effect of each of the explanatory variable on each of the possible outcomes (switching points in our case). This will allow us to rule out that the findings reported above are driven by the exclusion of behavior that is outside a certain range. Because very few observations fall in the left tail of the switching points, we report robust standard errors to control for sensitivity to outliers. The results are shown in table 9 .

As we can see, entrepreneurs significantly differ from others in only one of the outcomes: the likelihood of having a switching point of 4 (column $\omega=4$ ). Thus, the result we provide above in the equivalent OLS regression that removes extreme switching points (Model 1 in table 5) are not due to the fact that we have dropped some observations. There is thus evidence that our

\footnotetext{
${ }^{20}$ Although the ordered logit model seems to be appropriate given that spin scores are ordered, the Brant test indicates that the parallel regression assumption underlying the ordered logit model is violated.
} 
results are driven by the fact entrepreneurs are more likely to spin on higher numbers in the areas where it is reasonable for most people to have doubt about whether a second spin should be taken or not $(\omega \in\{3,4,5,6\})$.

The results in table 9 also point to non-linearities outside the range of reasonable actionorientedness $(\in\{0,1,2,7,8,9\})$. For instance, employees are less likely to have $\omega \in\{7,9\}$ but more likely to have $\omega=8$. This non-linearity could suggest that levels of action-orientedness are not ordered outside the reasonable region. This will in turn render linear regression analyses based on assumptions about the ordinal nature of action-orientedness inefficient. Given that fewer observations fall outside the reasonable range, it is more likely that the analysis of behavior outside the reasonable region be irrelevant. 
Table 9: Marginal effects predicting the liklihood of each outcome (switching point) from a multinomial logit regression model with the entire sample.

$$
\begin{array}{lllllllll}
\omega=0 & \omega=1 & \omega=2 & \omega=3 & \omega=4 & \omega=5 & \omega=6 & \omega=7 & \omega=8
\end{array}
$$

\begin{tabular}{lcccccccccc}
\hline Counterfactual information & -0.0064 & 0.0050 & 0.0016 & 0.0108 & $0.0413^{* *}$ & -0.0284 & $-0.0369^{*}$ & -0.0142 & 0.0081 & 0.0190 \\
& $(0.0091)$ & $(0.0059)$ & $(0.0052)$ & $(0.0120)$ & $(0.0188)$ & $(0.0255)$ & $(0.0223)$ & $(0.0125)$ & $(0.0123)$ & $(0.0144)$ \\
Male & 0.0072 & $0.0151^{* * *}$ & -0.0006 & $-0.0213^{*}$ & $0.0437^{* *}$ & -0.0089 & -0.0406 & 0.0029 & 0.0105 & -0.0079 \\
& $(0.0088)$ & $(0.0055)$ & $(0.0054)$ & $(0.0128)$ & $(0.0196)$ & $(0.0281)$ & $(0.0250)$ & $(0.0147)$ & $(0.0129)$ & $(0.0153)$ \\
Age & 0.0003 & -0.0001 & 0.0001 & 0.0003 & 0.0000 & -0.0013 & -0.0004 & 0.0001 & 0.0003 & 0.0006 \\
& $(0.0004)$ & $(0.0002)$ & $(0.0002)$ & $(0.0005)$ & $(0.0009)$ & $(0.0012)$ & $(0.0010)$ & $(0.0005)$ & $(0.0006)$ & $(0.0006)$ \\
Employee & -0.0128 & -0.0152 & -0.0069 & 0.0095 & $0.0595^{* *}$ & 0.0116 & -0.0338 & -0.0054 & 0.0113 & -0.0178 \\
& $(0.0123)$ & $(0.0113)$ & $(0.0128)$ & $(0.0148)$ & $(0.0237)$ & $(0.0354)$ & $(0.0304)$ & $(0.0182)$ & $(0.0151)$ & $(0.0190)$ \\
Manager & -0.0118 & 0.0047 & -0.0147 & 0.0069 & $0.0655^{* *}$ & -0.0622 & -0.0252 & 0.0131 & 0.0331 & -0.0093 \\
& $(0.0142)$ & $(0.0162)$ & $(0.0111)$ & $(0.0226)$ & $(0.0302)$ & $(0.0431)$ & $(0.0391)$ & $(0.0237)$ & $(0.0285)$ & $(0.0294)$ \\
Income dummies & Yes & Yes & Yes & Yes & Yes & Yes & Yes & Yes & Yes & Yes \\
Education dummies & Yes & Yes & Yes & Yes & Yes & Yes & Yes & Yes & Yes & Yes \\
\hline Observations & 1380 & 1380 & 1380 & 1380 & 1380 & 1380 & 1380 & 1380 & 1380 & 1380 \\
\hline \hline
\end{tabular}

Standard errors in parentheses

${ }^{*} p<0.1,{ }^{* *} p<0.05,{ }^{* * *} p<0.01,{ }^{* * * *} p<0.001$ 
Table 10: Probit regression estimating the likelihood of being an outlier. DV is one for outliers of action-orientedness and zero otherwise

\begin{tabular}{|c|c|}
\hline Manager & $\begin{array}{c}0.0581 \\
(0.1332)\end{array}$ \\
\hline Employee & $\begin{array}{c}-0.1651 \\
(0.1042)\end{array}$ \\
\hline Counterfactual information & $\begin{array}{c}0.0384 \\
(0.0760)\end{array}$ \\
\hline Male & $\begin{array}{c}0.0985 \\
(0.0837)\end{array}$ \\
\hline Age & $\begin{array}{c}0.0044 \\
(0.0035)\end{array}$ \\
\hline Vocational degree & $\begin{array}{c}-0.0731 \\
(0.1262)\end{array}$ \\
\hline College & $\begin{array}{c}-0.3759^{* * *} \\
(0.1315)\end{array}$ \\
\hline University & $\begin{array}{c}-0.7566^{* * * *} \\
(0.1513)\end{array}$ \\
\hline Income not provided & $\begin{array}{c}0.2053^{*} \\
(0.1165)\end{array}$ \\
\hline$€ 25,001-€ 50,000$ & $\begin{array}{l}-0.1105 \\
(0.1071)\end{array}$ \\
\hline$€ 50,001-€ 75,000$ & $\begin{array}{c}-0.1162 \\
(0.1537)\end{array}$ \\
\hline$€ 75,001-€ 125,000$ & $\begin{array}{c}-0.1643 \\
(0.1699)\end{array}$ \\
\hline More than $€ 125,001$ & $\begin{array}{c}-0.0224 \\
(0.2240)\end{array}$ \\
\hline Constant & $\begin{array}{c}-0.5929^{* *} \\
(0.2468) \\
\end{array}$ \\
\hline $\begin{array}{l}\text { Observations } \\
\text { df }\end{array}$ & $\begin{array}{c}1380 \\
13\end{array}$ \\
\hline p-value & 0.0000 \\
\hline Log likelihood & -723.16 \\
\hline
\end{tabular}

Standard errors in parentheses

${ }^{*} p<0.1,{ }^{* *} p<0.05,{ }^{* * *} p<0.01,{ }^{* * * *} p<0.001$ 